\title{
Silicon Nitride Based Coatings Grown by Reactive Magnetron Sputtering
}

\author{
Tuomas Hänninen
}


ISBN 978-91-7685-374-0

ISSN 0345-7524

Printed by LiU-Tryck 2018 
Abstract

Silicon nitride and silicon nitride-based ceramics have several favorable material properties, such as high hardness and good wear resistance, which makes them important materials for the coating industry. This thesis focuses the synthesis of silicon nitride, silicon oxynitride, and silicon carbonitride thin films by reactive magnetron sputtering. The films were characterized based on their chemical composition, chemical bonding structure, and mechanical properties to link the growth conditions to the film properties. Silicon nitride films were synthesized by reactive high power impulse magnetron sputtering (HiPIMS) from a Si target in $\mathrm{Ar} / \mathrm{N}_{2}$ atmospheres, whereas silicon oxynitride films were grown by using nitrous oxide as the reactive gas. Silicon carbonitride was synthesized by two different methods. The first method was using acetylene $\left(\mathrm{C}_{2} \mathrm{H}_{2}\right)$ in addition to $\mathrm{N}_{2}$ in a $\mathrm{Si}$ HiPIMS process and the other was co-sputtering of Si and C, using HiPIMS for Si and direct current magnetron sputtering (DCMS) for graphite targets in an $\mathrm{Ar} / \mathrm{N}_{2}$ atmosphere. Langmuir probe measurements were carried out for the silicon nitride and silicon oxynitride processes and positive ion mass spectrometry for the silicon nitride processes to gain further understanding on the plasma conditions during film growth. The target current and voltage waveforms of the reactive HiPIMS processes were evaluated.

The main deposition parameter affecting the nitrogen concentration of silicon nitride films was found to be the nitrogen content in the plasma. Films with nitrogen contents of 50 at.\% were deposited at $\mathrm{N}_{2} /$ Ar flow ratios of 0.3 and above. These films showed $\mathrm{Si}-\mathrm{N}$ as the dominating component in Si 2p X-ray photoelectron spectroscopy (XPS) core level spectra and $\mathrm{Si}-\mathrm{Si}$ bonds were absent. The substrate temperature and target power were found to affect the nitrogen content to a lower extent. The residual stress and hardness of the films were found to increase with the film nitrogen content. Another factors influencing the coating stress were the process pressure, negative substrate bias, substrate temperature, and HiPIMS pulse energy. Silicon nitride coatings with good adhesion and low levels of compressive residual stress were grown by using a pressure of $600 \mathrm{mPa}$, a substrate temperature 
below $200{ }^{\circ} \mathrm{C}$, pulse energies below $2.5 \mathrm{Ws}$, and negative bias voltages up to $100 \mathrm{~V}$. The elemental composition of silicon oxynitride films was shown to depend on the target power settings as well as on the nitrous oxide flow rate. Silicon oxide-like films were synthesized under poisoned target surface conditions, whereas films deposited in the transition regime between poisoned and metallic conditions showed higher nitrogen concentrations. The nitrogen content of the films deposited in the transition region was controlled by the applied gas flow rate. The applied target power did not affect the nitrogen concentration in the transition regime, while the oxygen content increased at decreasing target powers. The chemical composition of the films was shown to range from silicon-rich to effectively stoichiometric silicon oxynitrides, where no $\mathrm{Si}-\mathrm{Si}$ contributions were found in the XPS Si $2 \mathrm{p}$ core level spectra. The film optical properties, namely the refractive index and extinction coefficient, were shown to depend on the film chemical bonding, with the stoichiometric films displaying optical properties falling between those of silicon oxide and silicon nitride.

The properties of silicon carbonitride films were greatly influenced by the synthesis method. The films deposited by HiPIMS using acetylene as the carbon source showed silicon nitride-like mechanical properties, such as a hardness of $\sim 20 \mathrm{GPa}$ and compressive residual stresses of 1.7 - 1.9 GPa, up to film carbon contents of 30 at.\%. At larger film carbon contents the films had increasingly amorphous carbon-like properties, such as densities below $2 \mathrm{~g} / \mathrm{cm}^{3}$ and hardnesses below $10 \mathrm{GPa}$. The films with more than 30 at.\% carbon also showed columnar morphologies in cross-sectional scanning electron microscopy, whereas films with lower carbon content showed dense morphologies. Due to the use of acetylene the carbonitride films contained hydrogen, up to $\sim 15$ at.\%. The co-sputtered silicon carbonitride films showed a layered $\mathrm{SiN}_{\mathrm{x}} / \mathrm{CN}_{\mathrm{x}}$ structure. The hardness of these films increased with the film carbon content, reaching a maximum of $18 \mathrm{GPa}$ at a film carbon content of 12 at.\%. Comparatively hard and low stressed films were grown by co-sputtering using a $\mathrm{C}$ target power of $1200 \mathrm{~W}$ for a $\mathrm{C}$ content around 12 at. $\%$, a negative substrate bias less than $100 \mathrm{~V}$, and a substrate temperature up to $340{ }^{\circ} \mathrm{C}$. 


\section{Populärvetenskaplig sammanfattning}

Tunna filmer och beläggningar med tjocklekar som sträcker sig från delar av en nanometer till flera mikrometer spelar en viktig roll i många avancerade tillämpningar. De används för att förbättra ytegenskaperna hos material eller för att lägga till en ny funktion till det underliggande substratet. Några exempel är isoleringsbarriärer i elektronik, reflekterande beläggningar i optik och skyddande beläggningar för skärverktyg. Givet de tunna filmernas tekniska betydelse utvecklas även syntesteknikern. Några av de mest populära metoderna för tunnfilmssyntes innefattar elektroplätering som används inom bilindustrin och olika typer av kemiska och fysikaliska metoder som används i stor utsträckning inom halvledarindustrin. Magnetronsputtring, en syntesteknik som tillhör de fysiska metoderna, beskrivs mer detaljerat i denna avhandling.

Arbetet som presenteras här har genomförts inom projekt LifeLongJoints, huvudsakligen finansierat av Europeiska unionen. Ett av projektets mål var att utveckla biokompatibla slitstarka kiselnitridbaserade beläggningar för ortopediska implantat. I denna avhandling har reaktiva magnetronputtringprocesser för kiselnitridbaserade beläggningar, innefattande kiselnitrid, kiseloxynitrid och kiselkarbonitrid studerats. En stor del av arbetet har varit att karakterisera de syntetiserade beläggningarna samt att koppla depositionsparametrarna till filmegenskaper. Plasmakarakterisering med hjälp av masspektrometri och Langmuirsondmätningar har utförts för att få ytterligare förståelse för de reaktiva magnetronputtringsprocesserna och att sammansätta processförhållanden till filmegenskaper.

Filmerna karaktäriserades baserat på deras sammansättning, kemisk bindningsstruktur och mekaniska egenskaper. Kiselnitridfilmer syntetiserades genom reaktiv hög-effektspulsadmagnetronsputtring (HiPIMS) från en kiselkälla i argon och kvävgas, medan kiseloxynitridfilmer syntesiserades med lustgas i stället för kvävgas. Kiselkarbonitridfilmer syntetiserades med två olika metoder. Den första metoden använde acetylen förutom kvävgas som reaktiva gaser och den andra samputtring av kisel och kol i argon och kvävgas.

Den primära tillväxtparametern som påverkade kvävekoncentrationen av kisel- 
nitridfilmer var kvävehalten i plasmat. Filmer med kväveinnehåll av $50 \%$ erhölls vid $\mathrm{N}_{2} /$ Ar flödesförhållanden av 0,3 och högre. Hårda kiselnitridbeläggningar med låga spänningar syntetiserades genom användning av ett processtryck av $600 \mathrm{mPa}$, en substrattemperatur lägre än $200{ }^{\circ} \mathrm{C}$, pulsenergier under $2,5 \mathrm{Ws}$ och negativa biaspänningar upp till $100 \mathrm{~V}$.

Fördelningen mellan kväve och syre av kiseloxynitridfilmerna visade sig bero på effektsinställningarna av kiselkällan såväl som på lustgasflödeshastigheten. Kiseloxidliknande filmer syntetiserades med låg sputtringseffekt på kiselkällan och högt lustgasflöde, när kiseloxid bildades på källan. Kvävehalten i filmerna styrdes av gasflödeshastigheten och var oberoende av effekten på källan, när källan inte var förgiftad.

Egenskaperna av kiselkarbonitridfilmer påverkades starkt av syntesmetoden. Filmerna syntetiserade med HiPIMS och med acetylen som kolkälla visade kiselnitridliknande mekaniska egenskaper upp till kolinnehållet 30\%. De samsputtrade kiselkarbonitridfilmerna uppvisade en skiktad kiselnitrid/kolnitrid struktur. Jämförelsevis hårda och lågstressade filmer syntetiseras med användning av en effekt $1200 \mathrm{~W}$ på grafitkällan för en kolhalt omkring $12 \%$, en negativ substratförspänning lägre än $100 \mathrm{~V}$, och en substrattemperatur upp till $340{ }^{\circ} \mathrm{C}$. 
This thesis presents the results of my doctoral studies at Linköping University, at the department of physics, chemistry, and biology (IFM), between the years 2013 and 2018. Parts of the work in this thesis have appeared in my licentiate thesis, Silicon Oxynitride Thin Films Grown by Reactive HiPIMS, Linköping Studies in Science and Technology, Thesis no. 1737, 2015.

The work has received funding from the European Union's Seventh Framework Program (FP7/2007-2013) under the LifeLongJoints Project, Grant Agreement No. GA-310477, and from the Swedish Government Strategic Research Area in Materials Science on Functional Materials at Linköping University (Faculty Grant SFO-Mat-LiU No. 2009-00971). 



\section{Acknowledgements}

I want to express my gratitude to my supervisor Hans Högberg for his guidance during my studies. I am also thankful to my co-supervisors; Susann Schmidt for her invaluable help with the experimental work and article writing, and Lars Hultman for his insightful comments and questions.

In addition, I want to thank my co-authors and colleagues at the thin film physics division for their help, especially Thomas Lingefelt and Harri Savimäki for all the help with the equipment.

Lastly, I thank my family and Nina for their support. 

1 Introduction 1

1.1 Purpose and outline . . . . . . . . . . . . . . . . . 1

1.2 Silicon nitride and silicon nitride-based materials . . . . . . . . . 2

1.2.1 Silicon nitride . . . . . . . . . . . . . . . . 2

1.2.2 Silicon oxynitride . . . . . . . . . . . . . . . . . . 3

1.2.3 Silicon carbonitride. . . . . . . . . . . 5

2 Thin film deposition and process characterization 7

2.1 Magnetron sputtering ................... 8

2.1.1 High power impulse magnetron sputtering . . . . . . . . 9

2.1.2 Reactive sputtering . . . . . . . . . . . . . . 11

2.1.3 Sputtering with different reactive gases . . . . . . . . . 12

2.2 Plasma characterization . . . . . . . . . . . . . . 16

2.2.1 Langmuir probe measurements . . . . . . . . . . . . 16

2.2 .2 Mass spectrometry . . . . . . . . . . . . . . 17

2.3 Experimental details of thin film deposition . . . . . . . . . . . 19

3 Thin film characterization $\quad 21$

3.1 X-ray photoelectron spectroscopy . . . . . . . . . . . . . 21

3.2 Elastic recoil detection analysis . . . . . . . . . . . . . . . . . . . 24

3.3 X-ray reflectivity . . . . . . . . . . . . . . . . . 25

3.4 Raman spectroscopy .................... . . . . 27

3.5 Transmission electron microscopy . . . . . . . . . . . . . . . . . 28

3.6 Residual stress measurement . . . . . . . . . . . . . . . . . 30

3.7 Nanoindentation . . . . . . . . . . . . . . . . . . . . . . . . 32

3.8 Spectroscopic ellipsometry . . . . . . . . . . . . . . . 33

4 Summary of included publications $\quad 37$ 
$\begin{array}{ll}\text { Bibliography } & 43\end{array}$

Included publications and author's contribution $\quad 57$

$\begin{array}{ll}\text { Paper I } & 59\end{array}$

$\begin{array}{ll}\text { Paper II } & 69\end{array}$

$\begin{array}{ll}\text { Paper III } & 79\end{array}$

$\begin{array}{ll}\text { Paper IV } & 93\end{array}$

$\begin{array}{ll}\text { Paper V } & 103\end{array}$

$\begin{array}{ll}\text { Paper VI } & 115\end{array}$ 


\section{CHAPTER 1}

\section{Introduction}

Thin films and coatings with thicknesses ranging from parts of a nanometer to several micrometers play an essential part in many modern day technologies. They are used to enhance the surface properties of materials or to add new functionalities to the underlying substrate. Some examples include insulating barriers in electronic devices, anti-reflective coatings in optics, and protective coatings for cutting tools. Due the technological importance of thin films, also the synthesis methods are being vigorously developed. Some of the most popular thin film synthesis methods include electroplating used in car industry, and various types of chemical vapor deposition (CVD) and physical vapor deposition (PVD) methods used extensively in semiconductor industry. Magnetron sputtering, a thin film deposition technique belonging to the PVD methods, is covered in more detail in this thesis.

\subsection{Purpose and outline}

The work presented in this thesis has been conducted within the LifeLongJoints project which was mostly funded by the European Union. One of the the goals of the project was to develop biocompatible wear-resistant silicon nitride-based coatings for joint implants. In this context, the reactive magnetron sputtering processes for silicon nitride-based coatings, including silicon nitride, silicon oxynitride, and silicon carbonitride, have been studied. A major part of the work has been characterizing the synthesized coatings and connecting the deposition parameters to the film properties. Some plasma characterization by using mass spectrometry and Langmuir probe measurements have been carried out to gain further understanding on the reactive magnetron sputtering processes and to link the growth conditions to the film properties. 


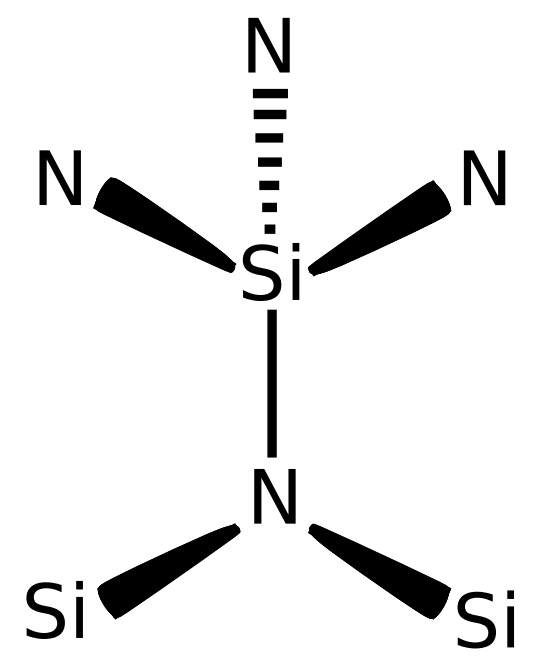

Figure 1.1. The covalent bonding structure of silicon nitride.

\subsection{Silicon nitride and silicon nitride-based mate- rials}

\subsubsection{Silicon nitride}

Silicon nitride was first synthesized in the 1800's. The industrial use of silicon nitride began in the 1950's as a refractory material. Naturally occurring silicon nitride can be found in meteorites in small quantities. [1] The chemical formula of stoichiometric silicon nitride is $\mathrm{Si}_{3} \mathrm{~N}_{4}$. It has three crystalline phases, the trigonal $\alpha$-Si ${ }_{3} \mathrm{~N}_{4}$, the hexagonal $\beta-\mathrm{Si}_{3} \mathrm{~N}_{4}$, and the high-pressure phase $\gamma-\mathrm{Si}_{3} \mathrm{~N}_{4}$. [1, 2] Silicon nitride is extensively used in hard coating industry due to its favorable mechanical properties, such as chemical stability, high hardness, and high resistance to wear and corrosion. [1] It is also used in microelectronics as an insulator and in diffusion barriers, owing to its high resistivity and dielectric strength and resistance to water diffusion. [1] Silicon nitride has also been studied as a material for medical implants. [3]

Recently, there has been a growing interest for amorphous silicon nitride $\left(\mathrm{SiN}_{\mathrm{x}}\right)$ coatings for metallic medical implants, in contrast to fully ceramic $\mathrm{Si}_{3} \mathrm{~N}_{4}$ implants. [4-9] The use of a ceramic coating on a metallic implant would combine the ductility of the metallic implant with the biocompatibility of the ceramic, without the risk of a catastrophic failure of a fully ceramic implant. [8] It has been shown that a $\operatorname{SiN}_{\mathrm{x}}$ coating can reduce implant corrosion and limit the metal ion release from metallic implants, thus reducing harmful inflammation in the surrounding tissue. [8] In addition to the favorable mechanical properties, such as high wear-resistance, $\operatorname{SiN}_{\mathrm{x}}$ wear debris is soluble in aqueous solutions, further reducing the risk of undesired reactions between the host and the implant. [9-11] 
The usual pathways to synthesize $\operatorname{SiN}_{\mathrm{x}}$ thin films include the various types of CVD and PVD processes. Films synthesized by CVD often show hydrogen as the main contaminant due to hydrogen-containing precursor gases. [1] When $\mathrm{SiN}_{\mathrm{x}}$ is synthesized by magnetron sputtering usually a $\mathrm{Si}$ target is sputtered in an $\mathrm{Ar} / \mathrm{N}_{2}$ atmosphere, although some studies have utilized a compound $\mathrm{Si}_{3} \mathrm{~N}_{4}$ target. [12] Because the nonconducting nature of silicon nitride causes problems in direct current magnetron sputtering, radio frequency $(\mathrm{RF})$ magnetron sputtering is often used. [12, 13]

The favorable mechanical properties of silicon nitride stem from its rigid covalent bonding structure consisting of $\mathrm{SiN}_{4}$ tetrahedra, shown in Fig. 1.1. [1] Thin films of silicon nitride are usually amorphous or polycrystalline and can contain impurities such as hydrogen and oxygen from the residual water vapor and used precursors, depending on the synthesis method. The possible incorporation of contaminants makes the amorphous thin films often nonstoichiometric, with $\mathrm{N} / \mathrm{Si}$ ratios deviating from the $4 / 3$ ratio of the stoichiometric compound. [1] Large hydrogen concentrations in silicon nitride films have been shown to result in deteriorated mechanical and optical properties. $[14,15]$ The mechanical properties, such as density and hardness, show a large range of values due to the large number of synthesis methods and varying amounts of contaminants. The amorphous $\operatorname{SiN}_{\mathrm{x}}$ films are usually less dense than crystalline $\mathrm{Si}_{3} \mathrm{~N}_{4}\left(3.2 \mathrm{~g} / \mathrm{cm}^{3}\right)$, up to $\sim 3 \mathrm{~g} / \mathrm{cm}^{3}$, depending on the processing conditions and amount of contaminants. [1] Mechanical properties, such as hardness, of amorphous $\mathrm{SiN}_{\mathrm{x}}$ films also show a wide range of values, from under $10 \mathrm{GPa}$ of understoichiometric contaminated films [16] to over $\sim 20 \mathrm{GPa}[12]$.

\subsubsection{Silicon oxynitride}

Silicon oxynitride is widely used in optoelectronics as graded-index layers [17, 18], waveguides $[19,20]$, and surface passivation layers, $[21,22]$ due to its favorable optical and electrical properties. Especially the tunable refractive index makes $\mathrm{SiO}_{\mathrm{x}} \mathrm{N}_{\mathrm{y}}$ well-suited for optical applications. [23] Furthermore, also the mechanical properties, such as residual stress and hardness can be controlled through the elemental composition. [24-26] Lately, there has been a growing interest for the use of $\mathrm{SiO}_{\mathrm{x}} \mathrm{N}_{\mathrm{y}}$ coatings in medical implants due to the good hemocompatibility of the material along with the suitable mechanical properties. [27, 28] The reason for such a wide range of applications for $\mathrm{SiO}_{\mathrm{x}} \mathrm{N}_{\mathrm{y}}$ is the possibility to control its material properties by adjusting the amount and ratio of oxygen and nitrogen in the material. This yields properties ranging from those of amorphous silicon to amorphous silicon oxide and nitride, or such shown by mixed compositions between the three constituents. $[29,30]$

Commonly $\mathrm{SiO}_{\mathrm{x}} \mathrm{N}_{\mathrm{y}}$ thin films have been prepared by either CVD or magnetron sputtering. The CVD methods are limited by hydrogen-containing precursor gases, resulting in $\mathrm{Si}-\mathrm{H}$ and $\mathrm{N}-\mathrm{H}$ chemical bonding in the films, which causes absorption losses in the near-infrared wavelength range. [19, 29, 31] Two reactive gases, $\mathrm{O}_{2}$ and $\mathrm{N}_{2}$, are usually employed when $\mathrm{SiO}_{\mathrm{x}} \mathrm{N}_{\mathrm{y}}$ is synthesized by magnetron sputtering. [32-34] The two-gas approach results in nonlinear target effects due 


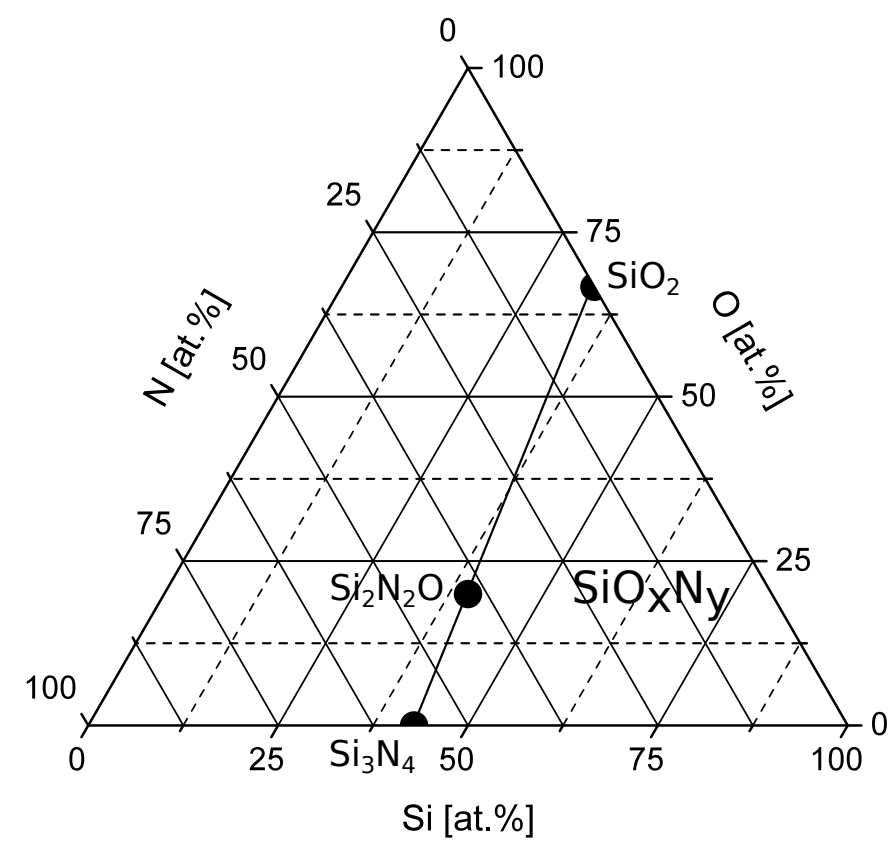

Figure 1.2. A ternary plot of the $\mathrm{Si}-\mathrm{O}-\mathrm{N}$ system.

to the inherently different reactivities of oxygen and nitrogen, since oxygen as the more reactive element is more likely to form a compound on the Si target. [35] Additional equipment, such as a reactive gas pulsing process or a feedback loop based on monitoring the discharge current or voltage, can be employed to limit the $\mathrm{O}_{2}$ flow during the process, and to reduce the nonlinear target effects caused by the different reactivities of oxygen and nitrogen. [32, 33, 36]

The $\mathrm{Si}-\mathrm{O}-\mathrm{N}$ system has only one thermodynamically stable ternary compound with the composition $\mathrm{Si}_{2} \mathrm{~N}_{2}$ O. [37, 38] A rare silicon oxynitride mineral known as sinoite can be found in some meteorites. [39] A ternary plot of the $\mathrm{Si}-\mathrm{O}-\mathrm{N}$ system is shown in Fig. 1.2. The chemical bonding in amorphous nonstoichiometric $\mathrm{SiO}_{\mathrm{x}} \mathrm{N}_{\mathrm{y}}$ can be described by two bonding models, the random mixture model (RMM) and the random bonding model (RBM). [40, 41] In RMM, separate phases of $\mathrm{SiO}_{2}$ and $\mathrm{Si}_{3} \mathrm{~N}_{4}$ are randomly distributed in the material, whereas in $\mathrm{RBM}$ the central $\mathrm{Si}$ atom is randomly bond to four $\mathrm{Si}, \mathrm{O}$, and/or $\mathrm{N}$ atoms. [40, 41] Commonly, the growth of $\mathrm{SiO}_{\mathrm{x}} \mathrm{N}_{\mathrm{y}}$ is more closely governed by RBM than by RMM, especially for sputter-deposited films, as the growth conditions are usually thermodynamically far from those required for the growth of separate $\mathrm{SiO}_{2}$ and $\mathrm{Si}_{3} \mathrm{~N}_{4}$ phases. [25, 42]

The material properties in the randomly bond $\mathrm{SiO}_{\mathrm{x}} \mathrm{N}_{\mathrm{y}}$ mostly depend on the ratio of $\mathrm{O}$ and $\mathrm{N}$ in the $\mathrm{Si}$-matrix. This can be achieved by changing the reactive gas flow ratios in reactive sputtering, for example. [43] The relative permittivity of stoichiometric $\mathrm{SiO}_{\mathrm{x}} \mathrm{N}_{\mathrm{y}}$ can vary from $3.9\left(\mathrm{SiO}_{2}\right)$ to $7.4\left(\mathrm{Si}_{3} \mathrm{~N}_{4}\right)$. [44] The refractive index of $\mathrm{SiO}_{\mathrm{x}} \mathrm{N}_{\mathrm{y}}$ can be tailored from that of $\mathrm{SiO}_{2}(n \sim 1.5)$ to that of $\mathrm{Si}_{3} \mathrm{~N}_{4}$ 
$(n \sim 2.0)$ by adjusting the $\mathrm{O} / \mathrm{N}$ ratio in the material. [17, 18] Furthermore, the refractive index for understoichiometric $\mathrm{SiO}_{\mathrm{x}} \mathrm{N}_{\mathrm{y}}$ are found to range from $\mathrm{Si}_{3} \mathrm{~N}_{4}$ values to those recorded for amorphous $\mathrm{Si}(n \sim 4)$, depending on how much $\mathrm{O}$ and $\mathrm{N}$ is incorporated into the Si-matrix. [45-47] The total amount of $\mathrm{O}$ and $\mathrm{N}$ in $\mathrm{SiO}_{\mathrm{x}} \mathrm{N}_{\mathrm{y}}$ affects the extinction coefficient $(k)$ values, the stoichiometric compound is found to be transparent $(k \sim 0)$ in the visible wavelength range, whereas for the understoichiometric compound the $k$ values increase as the amount of $\mathrm{Si}$ in the compound increases, finally reaching values recorded for amorphous $\operatorname{Si}(k \sim 0.2)$. $[46,47]$

Mechanical properties, such as density, residual stress, and hardness, depend on the the $\mathrm{O} / \mathrm{N}$ ratio of $\mathrm{SiO}_{\mathrm{x}} \mathrm{N}_{\mathrm{y}}$. The $\mathrm{SiO}_{\mathrm{x}} \mathrm{N}_{\mathrm{y}}$ density can vary from that of $\mathrm{SiO}_{2}$ $\left(\sim 2.1 \mathrm{~g} / \mathrm{cm}^{3}\right)$ to that of $\mathrm{Si}_{3} \mathrm{~N}_{4}\left(\sim 3.0 \mathrm{~g} / \mathrm{cm}^{3}\right)$. [48, 49] The residual stress in CVD-grown films can change from compressive to tensile, depending on if the material is oxide-like or nitride-like, respectively. [24] Moreover, both the hardness and elastic modulus of $\mathrm{SiO}_{\mathrm{x}} \mathrm{N}_{\mathrm{y}}$ films with random bonding is found to increase as the film composition shifts from $\mathrm{SiO}_{2}$ to $\mathrm{Si}_{3} \mathrm{~N}_{4}$, hardness from $\sim 10 \mathrm{GPa}$ to $\sim 20 \mathrm{GPa}$ and elastic modulus from $\sim 100 \mathrm{GPa}$ to $\sim 200 \mathrm{GPa} .[12,25]$

\subsubsection{Silicon carbonitride}

Similar to silicon nitride and silicon oxynitride, silicon carbonitride $\left(\mathrm{SiC}_{\mathrm{x}} \mathrm{N}_{\mathrm{y}}\right)$ has a wide range of applications. It is mostly known as a material for wear-resistant coatings due to its high corrosion and oxidation resistance, [50] but it also has uses in microelectronics and optics. [51, 52] As a ternary compound its material properties are highly dependent on the elemental composition. When it comes to medical applications, especially the favorable $\mathrm{SiN}_{\mathrm{x}}$-like mechanical properties and the potentially tunable dissolution rate make $\mathrm{SiC}_{\mathrm{x}} \mathrm{N}_{\mathrm{y}}$ a prominent candidate for a coating material to be used in joint implants. [13, 53]

The synthesis methods most commonly employed are pyrolysis of pre-ceramic polymers, [54, 55], CVD, [51, 56] and PVD. [57, 58] Various target-reactive gas combinations are possible for magnetron sputtering of $\mathrm{SiC}_{\mathrm{x}} \mathrm{N}_{\mathrm{y}}$. Carbon can be introduced either by sputtering a $\mathrm{SiC}$ target, [50] by reactive co-sputtering of $\mathrm{Si}$ and $\mathrm{C}$ targets, [5, 59] or by using a hydrocarbon gas such as methane [60] or acetylene [61]. Silicon carbonitride films are mostly amorphous, presenting properties similar to those of $\mathrm{SiN}_{\mathrm{x}}, \mathrm{CN}_{\mathrm{x}}$, or $\mathrm{SiC}$, depending on the composition. Possible crystalline phases in the $\mathrm{SiC}_{\mathrm{x}} \mathrm{N}_{\mathrm{y}}$ system have been proposed, in particular $\mathrm{Si}_{2} \mathrm{CN}_{4}$ and $\mathrm{SiC}_{2} \mathrm{~N}_{4}$, but their existence remains debated. [62, 63]

The chemical bonding structure in amorphous films is heavily influenced by the elemental composition and the synthesis method. In magnetron sputtered films a distinctive $\mathrm{Si}-\mathrm{N}$ component is often observed if nitrogen is abundant, [64] due to silicon preferably bonding to nitrogen rather than carbon [56]. Low film nitrogen contents favor the formation of $\mathrm{Si}-\mathrm{C}$ bonds. [58] Films sputtered with a hydrocarbon gas as a carbon source often have a pronounced $\mathrm{C}-\mathrm{C}$ component due to presence of amorphous hydrocarbon in the films. [59, 65] Similarly, co-sputtered films show a large $\mathrm{C}-\mathrm{C}$ contribution. [59]

Due to the wide range of synthesis methods, the $\mathrm{SiC}_{\mathrm{x}} \mathrm{N}_{\mathrm{y}}$ film properties vary 
remarkably. Hardness values under $10 \mathrm{GPa}$ are common for hydrogen-containing carbon-rich $\mathrm{SiC}_{\mathrm{x}} \mathrm{N}_{\mathrm{y}}$ films, [66] whereas some films can have hardnesses over $30 \mathrm{GPa}$ [51]. Similarly, mass density shows a wide range of values from under $2 \mathrm{~g} / \mathrm{cm}^{3}$ to $\sim 3 \mathrm{~g} / \mathrm{cm}^{3}$. [67] The same applies for optical properties, for example the refractive index can vary from 1.5 to 3.0. [68] 


\section{CHAPTER 2}

\section{Thin film deposition and process characterization}

Physical vapor deposition (PVD) methods, such as magnetron sputtering, are widely used both in research and in industry to grow a wide range of thin films for various applications. In PVD, the film material is ejected from a solid or liquid target and is transported to the substrate as a vapor. Usually PVD methods have a line-of-sight substrate coverage, unlike chemical vapor deposition (CVD) and atomic layer deposition (ALD) methods. The line-of-sight coverage limits the use of complex-shaped substrates in PVD deposition. Some advantages of PVD over CVD and ALD methods are, for example, off-thermal equilibrium film growth, allowing the use of heat-sensitive substrate materials, and higher deposition rates, respectively. Ionized PVD (IPVD) methods, such as high power impulse magnetron sputtering (HiPIMS), can be used to overcome shortages associated with common PVD methods, and open up possibilities to further tailor the film properties while still maintaining the favorable aspects of PVD. [69, 70] 


\subsection{Magnetron sputtering}

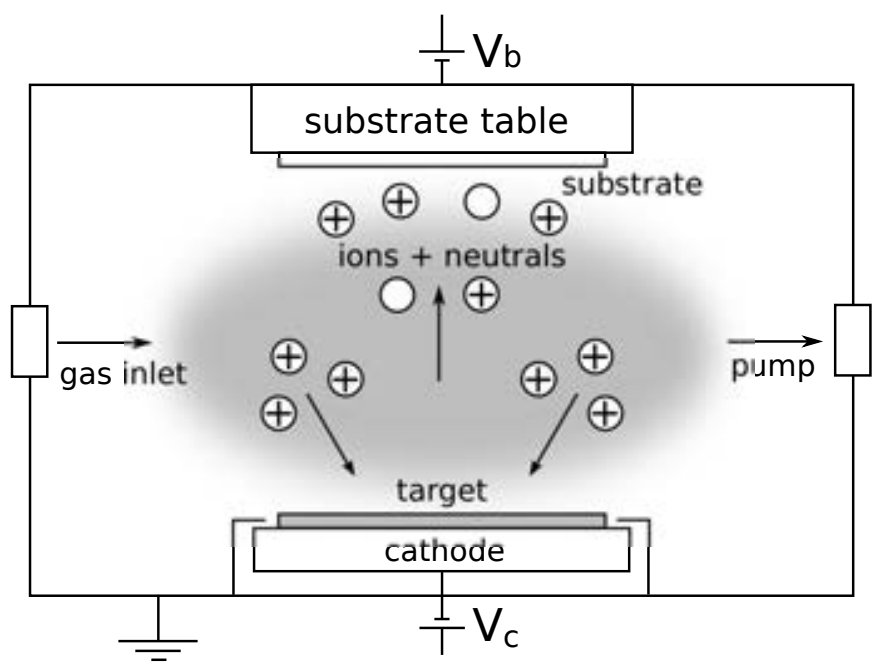

Figure 2.1. A schematic drawing of a magnetron sputtering setup.

Sputter deposition is a plasma-based PVD technique commonly employed in thin film growth. A potential difference applied between the negative cathode and a grounded anode causes ionization of the process gas, most commonly Ar, yielding a glow discharge according to Paschen's law. The ignition of the plasma is possible due to the ions and free electrons naturally present in the gas. More ions are created through collisions of the gas atoms with the free electrons, i.e., by electron impact ionization. Positive ionized gas atoms or molecules are accelerated towards the negatively biased cathode, where they sputter away material from the target. The ejected material travels to the substrate in the gas phase and condenses into a film. The grounded chamber walls and the substrate table can act as an anode, though usually a negative bias voltage is applied to the substrate table to exceed the floating potential and to achieve reproducible deposition conditions. [71, 72]

In a magnetron sputtering setup electrons are confined into a magnetic field near the target surface. Increased amount of electrons near the target surface enhances the level of ionization of the working gas and results in greater plasma density in the target vicinity. The working pressure can be decreased due to the increased plasma density, resulting in decreased collisional energy loss of the target bombarding ions in the gas phase, and thus enhanced sputtering rates. [73] A simple schematic drawing of a magnetron sputtering setup is shown in Fig. 2.1. Typical gas pressures used in magnetron sputtering are in the range of $100 \mathrm{mPa}-10 \mathrm{~Pa}$, depending on the dimensions of the sputtering system, affecting the pressure required to ignite and maintain a plasma. [74] Usually the magnets are arranged in a ring-like pattern, with one pole in the center and the opposite pole circling it. Figure 2.2 shows a balanced magnetron configuration, i.e., closed-loop magnetic field lines, which 


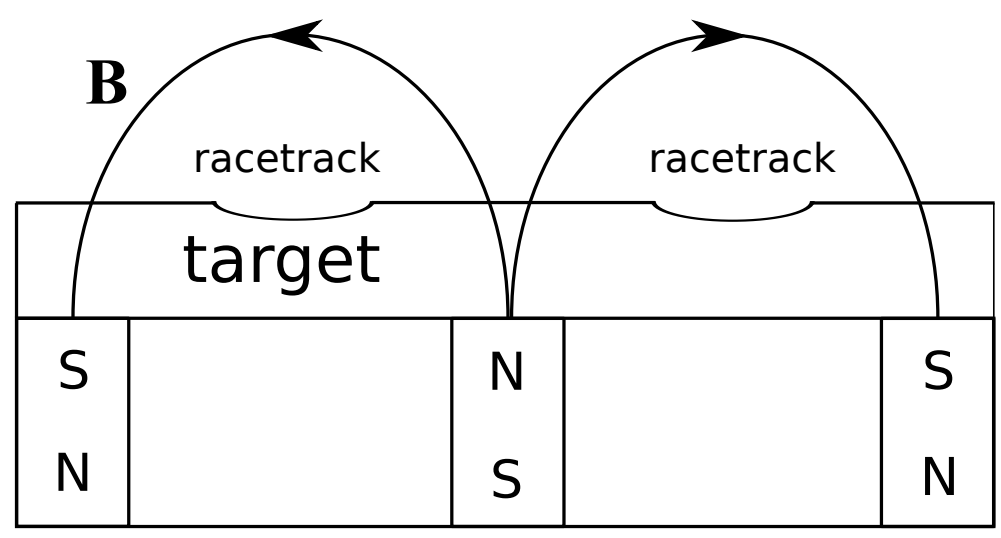

Figure 2.2. A drawing depicting the orientation of magnetic field lines in a simple balanced magnetron sputtering setup.

results in a dense plasma contained in the target vicinity. Enhanced sputtering over a certain area of the target may result in a so-called racetrack target erosion pattern. Additionally, an unbalanced magnetron setup can be used, resulting in open magnetic field lines and an increased plasma density away from the target, promoting ion bombardment of the growing film. The applied magnetic field configurations affect the ion-to-metal flux ratio arriving at the substrate, and can be used to tailor the morphology and properties of the growing film. [71, 72]

\subsubsection{High power impulse magnetron sputtering}

High power impulse magnetron sputtering (HiPIMS) is an IPVD technique introduced in the 1990's. [75] In HiPIMS the power to the cathode is delivered in short unipolar pulses with a relatively long halt time between the pulses $(\sim 1-10 \mathrm{~ms})$. The pulse frequencies used in HiPIMS can range from a few tens of $\mathrm{Hz}$ to a few $\mathrm{kHz}$, and the pulse on-time from a few microseconds to several hundreds of microseconds. The power on/off ratios during the cycle (duty cycle) vary from a few percent to a few tens of percent. The high energy delivered per pulse results in increased plasma densities in front of the target, which in turn leads to elevated amounts of ionized sputtered material due to electron impact ionization. In HiPIMS discharges the plasma density can reach values up to $10^{19}$ ions $/ \mathrm{cm}^{3}$, for direct current magnetron sputtering (DCMS) discharges the peak plasma densities are two or three orders of magnitude lower. The use of high power pulses allows effective target cooling even when the power delivered to the cathode during the pulse on-time exceeds the time-averaged power by two orders of magnitude, and can reach values as high as several $\mathrm{kW} / \mathrm{cm}^{2}$. In DCMS processes the target powers usually fall in the range of some tens or hundreds of $\mathrm{W} / \mathrm{cm}^{2}$. An example of a HiPIMS target current and voltage waveforms recorded for a process done with an average target power of $2400 \mathrm{~W}$, a frequency of $600 \mathrm{~Hz}$, a pulse width of $200 \mu \mathrm{s}$, and at a pressure of $400 \mathrm{mPa}$ employing a $\mathrm{N}_{2} \mathrm{O} / \mathrm{Ar}$ flow ratio of $12.8 \%$ is shown in Fig. 2.3. The target 


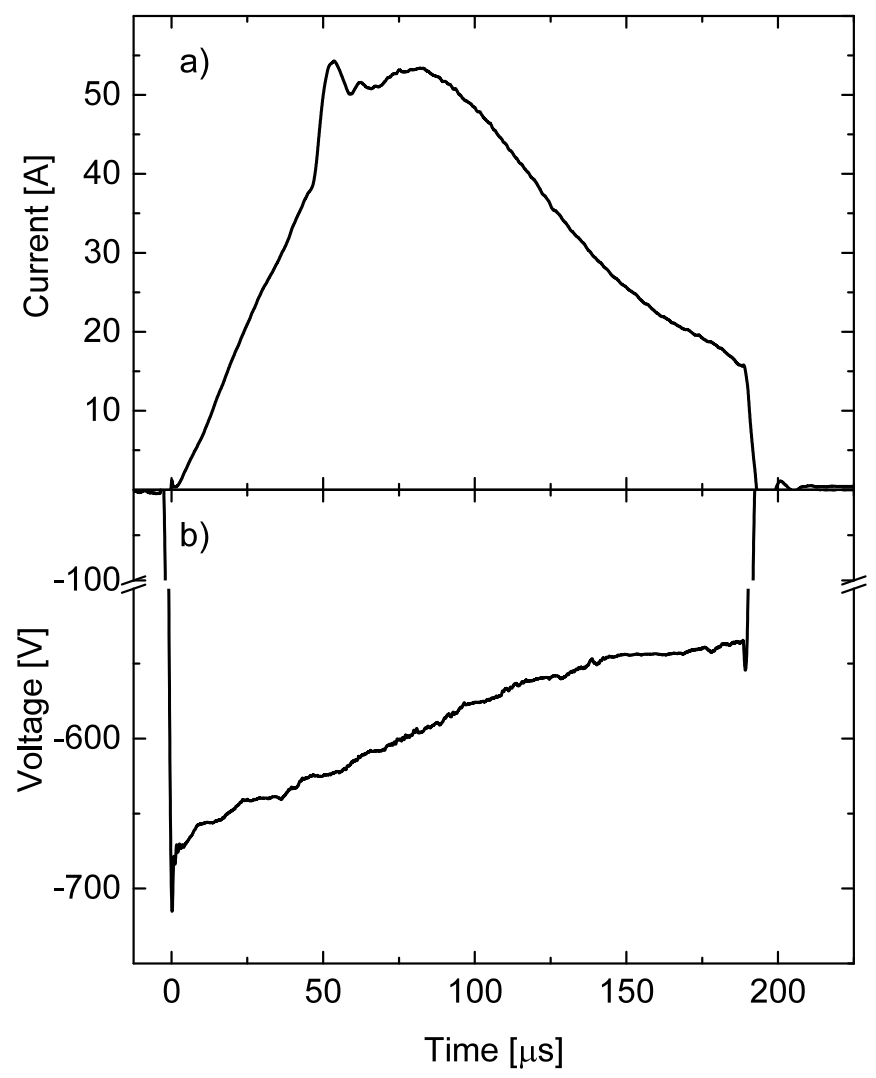

Figure 2.3. An example of target current and voltage waveforms with a $200 \mu$ s pulse.

voltage is not constant throughout the pulse due to depletion of the capacitor bank of the power supply. [76-78]

Thin film processing by HiPIMS mostly relies on the increased portion of ionized target material when compared to DCMS. The higher degree of ionization of the sputtered material results in increased ion bombardment of the substrate and the growing film. [75, 79, 80] For this reason, HiPIMS is found to yield denser films with a glass-like microstructure, when compared to films grown by DCMS that often have a more columnar appearance. [81, 82] The energy and direction of the ionized flux arriving at the substrate can be controlled by electric or magnetic fields, allowing off-axis deposition on complex-shaped substrates. [83, 84] For example, the energy of the ions impinging on the substrate and the growing film can be tuned by adjusting the substrate bias voltage, thus affecting the microstructure and the residual stresses of the growing film. [80] This opens up a possibility to tailor the electrical and optical properties of the films, as those properties depend on the microstructure. [80, 85-88]

HiPIMS also has its limitations. One major drawback is the low deposition rate 
of some materials compared to DCMS, when both are operated at the same average target power. [89] The deposition rates for HiPIMS can be half of the DCMS rate or even lower for some metals, for example $\mathrm{Ti}, \mathrm{Al}$, and $\mathrm{Cr}$, though for some oxides, e.g., $\mathrm{ZrO}_{2}$ and $\mathrm{Ta}_{2} \mathrm{O}_{5}$, the HiPIMS deposition rate can exceed that obtained by DCMS. [76, 81, 90] Some explanations proposed for lowered deposition rates include magnetic confinement of the sputtered species [84], non-linear energetic dependence of the sputter yield [91], the effects caused by plasma conductivity [92], and back-attraction of charged target metal ions [93]. Another concern is the existence of multiply charged target metal ions, which are accelerated into higher kinetic energies by the substrate bias and can cause undesirable effects, such as ion implantation and higher residual stresses in the films. [94]

\subsubsection{Reactive sputtering}

In reactive sputtering, the target is sputtered in the presence of one or more reactive gases, either mixed in with the neutral gas or completely replacing it. When a reactive gas, for example $\mathrm{O}_{2}, \mathrm{~N}_{2}$, or a hydrocarbon gas such as $\mathrm{C}_{2} \mathrm{H}_{2}$, is introduced to the chamber it is likely to react with the target surface by chemisorption and reactive ion implantation, and with the sputtered target material at the substrate as well as with the chamber walls, forming a compound. [95, 96]

The compound film formation at the target surface is known as target poisoning. [97] The transition between the metallic and poisoned target surface conditions is often observed as sudden changes in the cathode voltage and current, gas pressure, and deposition rate. $[98,99]$ The target current is made of the ion current to the target and partly due to the secondary electron emission from it, according to equation (2.1): [77]

$$
I=I_{\mathrm{i}}+I_{\mathrm{SE}}=\left(1+\gamma_{\mathrm{SE}}\right) I_{\mathrm{i}},
$$

where $I_{\mathrm{i}}$ is the ionic current, $I_{\mathrm{SE}}$ is the secondary electron current, and $\gamma_{\mathrm{SE}}$ is the secondary electron emission yield of the target. The secondary electron emission yield can be estimated by using the following empirical relation: [100]

$$
\gamma_{\mathrm{SE}}=0.032\left(0.78 E_{\mathrm{P}}-2 \phi\right) \text {, }
$$

where $E_{\mathrm{P}}$ is the potential energy of the arriving ion, which is often the first ionization energy, and $\phi$ is the target surface work function. Thus the changes in plasma composition and the compound formation on target surface affect the discharge current.

Reactive sputtering processes often show hysteresis in relation to the reactive gas flow and the change in target surface conditions. This means that once the poisoned surface conditions have been achieved the reactive gas flow has to be lowered significantly to reach metallic surface conditions again. The magnitude of hysteresis is dependent on the sputter yields of the clean target material and the compound, and also on the pumping speed of the system. [101] The high peak powers used in HiPIMS allow better control over the onset of target poisoning by efficiently removing the poisoned surface layer during the pulse. [102, 103] Moreover, target poisoning by reactive gas ion implantation between the pulses 
is limited, reducing the compound formation on the target. [76, 102] This is an advantage compared to DCMS, as growth of stoichiometric compound films often requires the deposition process to be run in the transition regime between metallic and poisoned target surface conditions, to achieve both the desired composition and an ample deposition rate. [102, 104]

\subsubsection{Sputtering with different reactive gases}

The reactive gases employed in reactive sputtering have a major role defining the behavior of the sputtering process. The gases not only provide the element of interest for compound formation, but due to their inherent chemical and physical properties, such as reactivity and ionization energy, the whole sputtering process is greatly affected by the choice of reactive gas. The following discussion focuses on the three gases that were used in the work presented in this thesis, $\mathrm{N}_{2}, \mathrm{~N}_{2} \mathrm{O}$, and $\mathrm{C}_{2} \mathrm{H}_{2}$.

\section{Nitrogen}

Nitrogen is commonly used in magnetron sputtering of metal nitrides, especially in the hard coating industry. Once nitrogen is introduced to the sputtering system, several reactions between the nitrogen molecule $\left(\mathrm{N}_{2}\right)$ and the plasma electrons can take place. The picture is more complicated than in the case of a monoatomic gas, since the $\mathrm{N}_{2}$ molecule can also dissociate and in addition it has vibrational and rotational states that can be excited. [105]

The $\mathrm{N}_{2}$ molecule has an ionization energy of $15.6 \mathrm{eV}$ and can be ionized by electron impact according to the following reaction: [106]

$$
\mathrm{N}_{2} \stackrel{\mathrm{e}^{-}}{\rightarrow} \mathrm{N}_{2}^{+}+2 \mathrm{e}^{-}
$$

Another possible electron impact reaction is dissociative ionization with an energy threshold of $24.3 \mathrm{eV}$ : [107]

$$
\mathrm{N}_{2} \stackrel{\mathrm{e}^{-}}{\rightarrow} \mathrm{N}^{+}+\mathrm{N}+2 \mathrm{e}^{-}
$$

The $\mathrm{N}_{2}$ molecule can also dissociate without ionization, yielding two $\mathrm{N}$ atoms. [108] Another contributing factor to the dissociation and ionization of $\mathrm{N}_{2}$ is the neutral gas, in this case Ar, allowing for example Penning ionization of $\mathrm{N}_{2}$ by metastable Ar species and charge transfer reactions. [109, 110] In HiPIMS plasmas, however, the electron impact reactions can be expected to dominate over the other mechanisms due to the high plasma density and high electron energy. [111]

The nitride compound growth on a silicon target surface is seen as a decrease in discharge current. [112] This is due the high surface work function of the compound $(\sim 7 \mathrm{eV})[113]$ compared to that of a clean Si surface $(4.6 \mathrm{eV})$ [114], resulting in a decreased secondary electron emission from the target according to equation (2.2). In PAPER III, target poisoning due to nitride compound growth was observed at a comparably high $\mathrm{N}_{2} /$ Ar flow ratio of 0.5 , due to low reactivity of nitrogen with silicon. [112] At lower $\mathrm{N}_{2} /$ Ar flow ratios of 0.3 a small increase in peak target 
current was observed, which was associated a larger number ions in target vicinity as a result of dissociation of $\mathrm{N}_{2}$, rather than being caused by the slightly lower ionization energy of $\mathrm{N}_{2}(15.6 \mathrm{eV})$ to that of argon $(15.8 \mathrm{eV})$ [115].

\section{Nitrous oxide}

Oxygen as a highly reactive element is the major cause behind the effects that were observed for $\mathrm{N}_{2} \mathrm{O}$. First, as $\mathrm{N}_{2} \mathrm{O}$ is introduced to the HiPIMS process, the $\mathrm{N}_{2} \mathrm{O}$ molecule can be ionized or dissociatively ionized as a result of electron impact. The ionization energy of $\mathrm{N}_{2} \mathrm{O}$ is $12.9 \mathrm{eV}$. [116] The dissociative ionization products of $\mathrm{N}_{2} \mathrm{O}$ include $\mathrm{NO}^{+}, \mathrm{O}^{+}, \mathrm{N}_{2}^{+}$and $\mathrm{N}^{+}$. Both $\mathrm{NO}^{+}$and $\mathrm{O}^{+}$with a threshold of $15.3 \mathrm{eV}$ are energetically more favorable than $\mathrm{N}_{2}{ }^{+}(17.3 \mathrm{eV})$ or $\mathrm{N}^{+}(20.3 \mathrm{eV})$. $[117,118]$ In addition, the electron impact cross-sections of $\mathrm{NO}^{+}$and $\mathrm{O}^{+}$yielding reactions are larger. $[117,118]$ The $\mathrm{N}_{2} \mathrm{O}$ molecule can undergo dissociative electron attachment to yield $\mathrm{O}^{-}$ions, according to the following pathway:

$$
\mathrm{N}_{2} \mathrm{O} \stackrel{\mathrm{e}^{-}}{\rightarrow} \mathrm{O}^{-}+\mathrm{N}_{2}
$$

The reaction occurs already at zero electron energies when the gas temperature is above the room temperature. [119] Additionally, the attachment cross-section increases with gas temperature and its values can reach the same order of magnitude as the electron impact ionization cross-section.[119] Based on the above discussion, it can be expected that ionized oxygen species are found in $\mathrm{N}_{2} \mathrm{O}$-containing HiPIMS plasmas.

The high reactivity of oxygen results in pronounced target poisoning, yielding highly unstable transition region conditions. Sputtering under poisoned target surface conditions often results in arcing of the target, and can produce undesirable macroparticles and decrease the film quality. [120, 121] Various reactive gas flow feedback systems, such as reactive gas partial pressure sensing and reactive gas pulsing, have been employed to maintain the process in the transition regime. $[90,122]$ Another possibility to achieve controllable deposition processes in the poisoned mode is to use arc suppression. [103, 123] The synthesis of oxynitrides by using both $\mathrm{O}_{2}$ and $\mathrm{N}_{2}$ as reactive gases is made more difficult by the nonlinear target effects caused by the different reactivities of $\mathrm{O}_{2}$ and $\mathrm{N}_{2}$. [33, 35] Due to the higher reactivity of oxygen compared to nitrogen, it is more probable that the target is trapped into the poisoned state by oxygen if the reactive gas flows are not accurately controlled. [124] A pathway to achieve more controllable rHiPIMS deposition processes for $\mathrm{SiO}_{\mathrm{x}} \mathrm{N}_{\mathrm{y}}$ by using nitrous oxide $\left(\mathrm{N}_{2} \mathrm{O}\right)$ as a single-source precursor gas is presented in PAPERS I and II.

As an electronegative element, oxygen is found to yield $\mathrm{O}^{-}$ions in rHiPIMS plasmas. [125, 126] These negative ions are repelled by the applied negative cathode potential and can have deteriorating effects on film quality, depending on their origin and energy. [125, 127, 128] Low energy negative ions can be generated via electron attachment to gas atoms or molecules, dissociative electron attachment to gas molecules, or by fragmentation of the sputtered target compound. [126] Ion energies corresponding to the applied cathode potential of several hundreds of volts have been measured for $\mathrm{O}^{-}$ions originating from the target surface. [128] The $\mathrm{O}^{-}$ 
ions existing in the afterglow of the rHiPIMS pulse can potentially contribute to the film oxygen uptake even during the pulse off-time. [125]

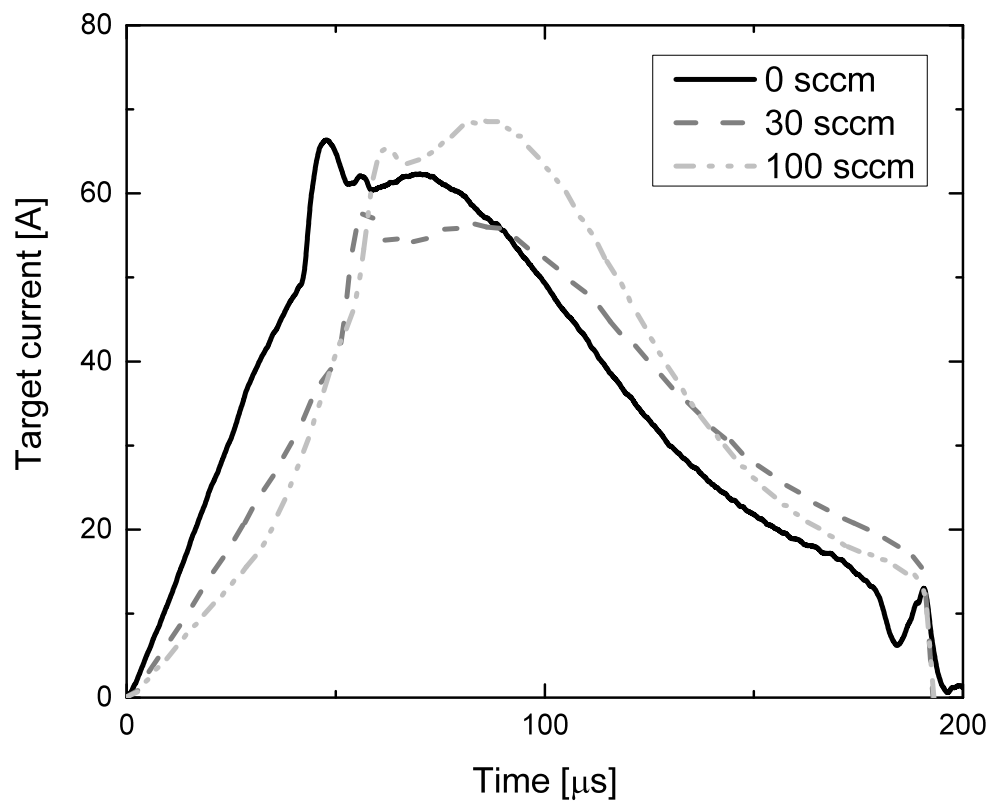

Figure 2.4. The evolution of the target current with $\mathrm{N}_{2} \mathrm{O}$ flow.

The oxide compound formation at the target surface in the case of using silicon as target material is observed as a rise in peak target current due to higher secondary electron yield of silicon oxide compared to silicon. [100, 129] Figure 2.4 shows the target current waveform evolution as the percentage of nitrous oxide in the plasma is increased, using an average target power of $4000 \mathrm{~W}$ and a pulse frequency of $1000 \mathrm{~Hz}$, at a pressure of $400 \mathrm{mPa}$. A noticeable delay in target current growth is seen as the $\mathrm{N}_{2} \mathrm{O}$ flow is increased and the peak target current shifts later into the pulse compared to a nonreactive process. This behavior can be attributed to postponed breakdown of the process gas due energy loss of electrons in front of the target. [130] The energy loss is due to excitation of the $\mathrm{N}_{2} \mathrm{O}$ molecules, owing to dissociation and excitation of the vibrational and rotational states of the molecule. [117, 118, 130, 131] Initially, the peak target current decreases as more nitrous oxide is introduced. This can be attributed to the decreasing plasma density in front of the target and thus decreasing plasma conductivity [132-134], and to reduced secondary electron emission from silicon suboxides [98], limiting the current that can be drawn to the cathode. After a certain threshold the peak current starts increasing, indicating poisoned target surface conditions, because the secondary electron emission yield from completely oxidized silicon surface is higher than that from clean silicon or suboxides. [98, 100, 129] Eventually the target current grows larger than that of the clean Si target, as is the case for a 
$\mathrm{N}_{2} \mathrm{O}$ flow of 100 sccm, shown in Fig. 2.4.

\section{Acetylene}

Hydrocarbon gases such as acetylene $\left(\mathrm{C}_{2} \mathrm{H}_{2}\right)$ and methane $\left(\mathrm{CH}_{4}\right)$ are commonly used to synthesize amorphous carbon thin films and metal carbides by magnetron sputtering. [135-137] They have been used as the carbon source for SiCN films, where $\mathrm{N}_{2}$ was used to supply nitrogen, resulting in a complex sputtering process with more than one reactive gas. [58, 60]

Several electron impact reactions are possible for the $\mathrm{C}_{2} \mathrm{H}_{2}$ molecule. Electron impact ionization has an energy threshold of $11.4 \mathrm{eV}$ [105], which is significantly lower than that of $\mathrm{Ar}(15.8 \mathrm{eV})$ or $\mathrm{N}_{2}(15.6 \mathrm{eV})$. In addition, the ionization crosssection of $\mathrm{C}_{2} \mathrm{H}_{2}$ is higher than those of $\mathrm{Ar}$ [138] or $\mathrm{N}_{2}$ [106], implying that ionization of $\mathrm{C}_{2} \mathrm{H}_{2}$ favored in $\mathrm{Ar} / \mathrm{N}_{2} / \mathrm{C}_{2} \mathrm{H}_{2}$ mixtures. Also the dissociative ionization products $\mathrm{C}_{2} \mathrm{H}^{+}, \mathrm{C}_{2}{ }^{+}, \mathrm{H}^{+}$, and $\mathrm{C}^{+}$are possible, but have higher energy thresholds than pure ionization. [139] The $\mathrm{C}_{2} \mathrm{H}_{2}$ molecule can dissociate into $\mathrm{C}_{2} \mathrm{H}$ and $\mathrm{H}$ radicals with a threshold energy of $7.5 \mathrm{eV}$, which further increases the number of reactive hydrocarbon species in the plasma. [140]

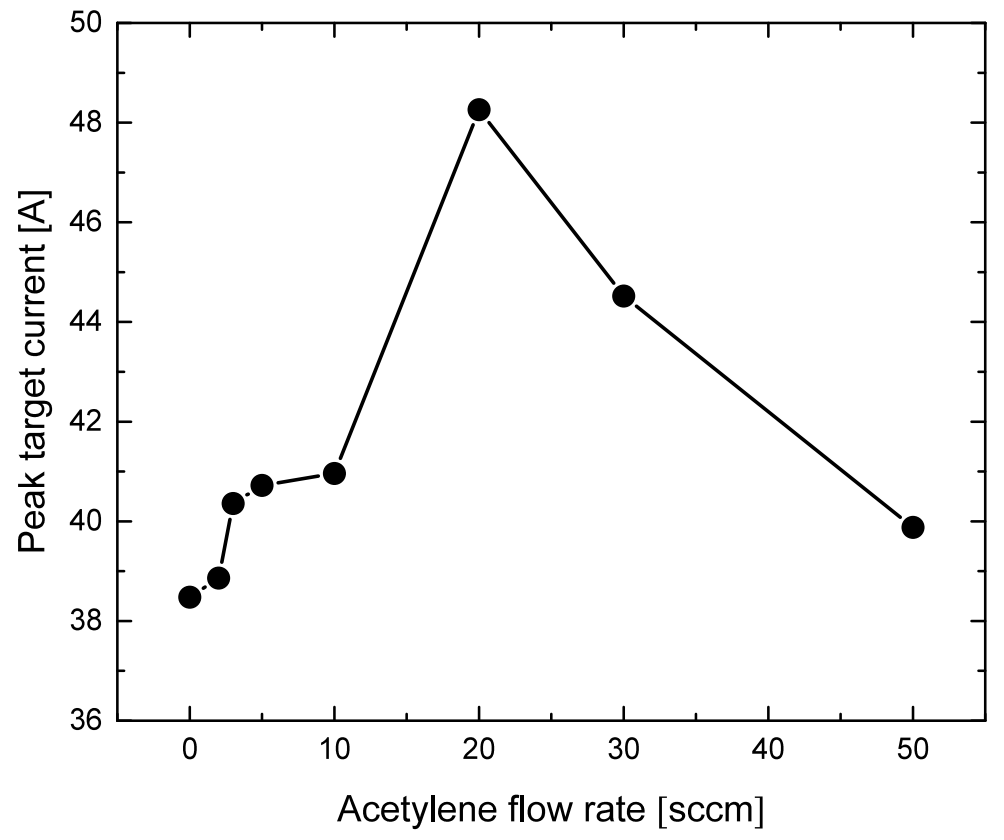

Figure 2.5. The Si target peak current as a function of $\mathrm{C}_{2} \mathrm{H}_{2}$ flow rate.

The reactive sputtering process with $\mathrm{C}_{2} \mathrm{H}_{2}$ is inherently different compared to those using $\mathrm{O}_{2}$ or $\mathrm{N}_{2}$, because a hydrogen-containing carbon layer consisting only of the supplied gas can form on the target surface, whereas both oxygen and nitrogen need to form a compound with the target material. [135, 141] 
This leads to some peculiar properties, such as a plasma CVD-like process where amorphous carbon films can be deposited from a heavily poisoned metal target. [137, 142] Similar behavior was observed in PAPER V for a Si target sputtered in $\mathrm{Ar} / \mathrm{N}_{2} / \mathrm{C}_{2} \mathrm{H}_{2}$ plasmas, where increasing $\mathrm{C}_{2} \mathrm{H}_{2}$ flow rates resulted in increasing film carbon contents, replacing equally both silicon and nitrogen. Here, the $\mathrm{Ar} / \mathrm{N}_{2}$ flow rate was fixed to 0.28 to yield a pressure of $400 \mathrm{mPa}$ and pressure was allowed to increase as $\mathrm{C}_{2} \mathrm{H}_{2}$ was introduced. Figure 2.5 shows the Si target peak current versus the applied $\mathrm{C}_{2} \mathrm{H}_{2}$ flow rate. The initially increasing peak target currents were assigned to increased ion bombardment of the target, owing to the large number of ionized hydrocarbon species present in the plasma, and partly to altered target surface chemistry. Decreasing peak target currents seen for $\mathrm{C}_{2} \mathrm{H}_{2}$ flows higher than $20 \mathrm{sccm}$ were linked to decreased secondary electron emission due to greater number of target-bombarding ions being hydrocarbon species. This results in lower secondary electron emission yield according to equation (2.2), as the ionization energy of $\mathrm{C}_{2} \mathrm{H}_{2}$ is lower than those of $\mathrm{Ar}$ or $\mathrm{N}_{2}$. An amorphous carbon-rich target surface can also contribute to lower secondary electron emission [143], compared to silicon [114] or nitrogen-rich hydrocarbon [144].

\subsection{Plasma characterization}

\subsubsection{Langmuir probe measurements}

Plasma parameters in the HiPIMS discharge can be measured by using a Langmuir probe. $[145,146]$ The probe has to be small to minimize perturbations caused to the plasma. As the probe bias is swept from negative to positive voltages, both ions and electrons are collected by the probe and an $I-V$ curve is recorded. These curves can be measured dynamically to record the $I-V$ curves during different stages of the pulse. An ideal $I-V$ curve is shown in Fig. 2.6. At the floating potential $\left(V_{f}\right)$ the ion and electron currents drawn by the probe are equal and probe current $\left(I_{p}\right)$ is nil. At the plasma potential $\left(V_{p}\right)$ the probe is in the same potential as the plasma itself, and the probe current is mostly resulting from electrons. [147]

Three different curve regions can be identified based on the applied probe bias $\left(V_{b}\right)$. When $V_{b}<V_{f}$, electrons are repelled and $I_{p}$ is mainly caused by ions, until the ion saturation current $\left(I_{i, s a t}\right)$ is reached at large negative $V_{b}$. At $V_{b}>V_{p}$, only negative charge carriers are being collected by the probe and eventually the electron saturation current $\left(I_{e, s a t}\right)$ is reached. [147]

Between $V_{f}$ and $V_{p}$, increasing amount of electrons are being collected by the probe. At a certain $V_{b}$ only those electrons that have enough energy to overcome the potential difference between the probe and the plasma are collected. In the case of a Maxwellian energy distribution of electrons, the electron current collected by the probe in this region follows equation (2.6):

$$
I_{e}=I_{e, s a t} \exp e \frac{V_{b}-V_{p}}{k_{B} T_{e}},
$$

where $k_{B}$ is the Boltzmann constant and $T_{e}$ is the average electron temperature. The slope of $\ln I_{e}$ versus $V_{p}$ yields the electron temperature. It is convenient to 


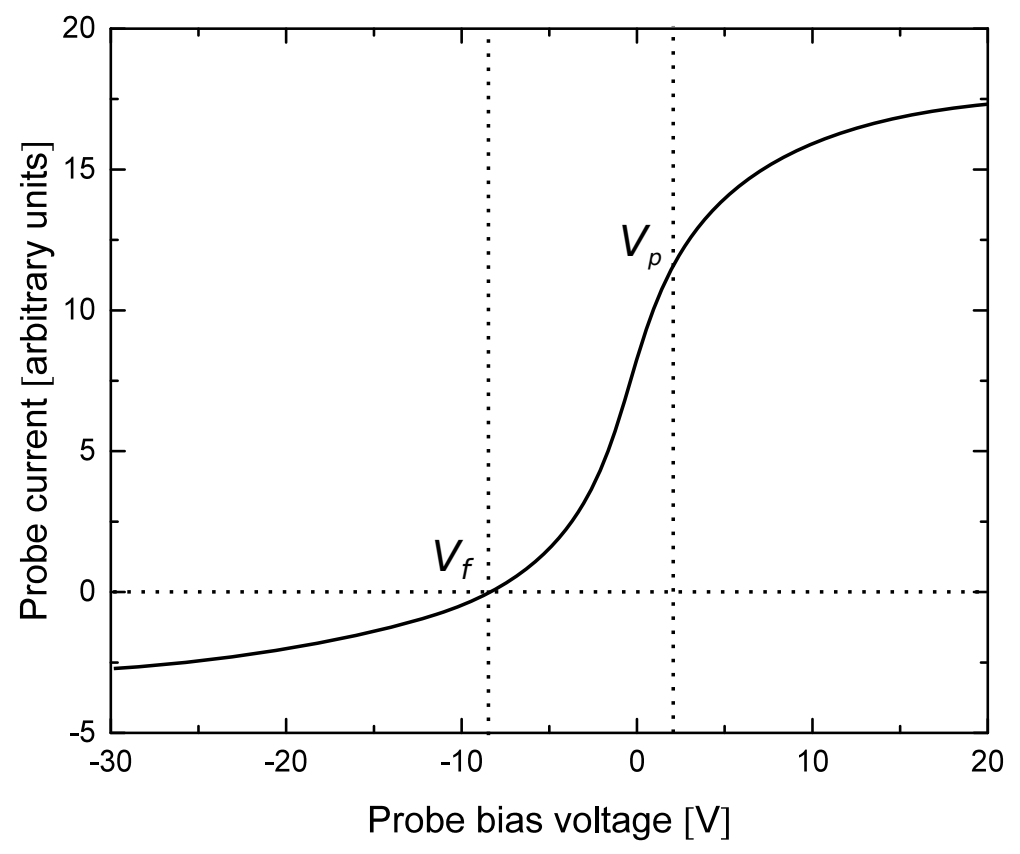

Figure 2.6. An ideal Langmuir probe $I-V$ curve, showing both $V_{f}$ and $V_{p}$.

give $T_{e}$ in electronvolts, by using the inverse of the slope. [147]

A custom built Langmuir probe system was used in PAPERS II and III to measure the electron temperature. Time-resolved measurements were performed to measure the $I-V$ curves during the peak target current of the HiPIMS pulse. The chosen $I-V$ curves were analyzed manually by extracting the electron temperature from the slope of electron current versus the probe current in a semilogarithmic scale. The main finding of the Langmuir study was that the electron temperature was increasing with the amount of $\mathrm{N}_{2} \mathrm{O}$ in the plasma, as is presented in Fig. 2.7. The electron temperature was found to increase rapidly from $2.8 \mathrm{eV}$ of the non-reactive process when only a small amount of $\mathrm{N}_{2} \mathrm{O}$ was introduced. At a $\mathrm{N}_{2} \mathrm{O}$ flow of $10 \mathrm{sccm}$, corresponding to a $2.3 \% \mathrm{~N}_{2} \mathrm{O} /$ Ar flow ratio, $T_{\text {e }}$ rose to $4.6 \mathrm{eV}$, a $1.8 \mathrm{eV}$ increase from $2.8 \mathrm{eV}$. An increasing $T_{\mathrm{e}}$ was observed though the studied flow range, $T_{\mathrm{e}}$ reaching a maximum of $7.2 \mathrm{eV}$ at a $\mathrm{N}_{2} \mathrm{O}$ flow of $60 \mathrm{sccm}$. The increase in $T_{\mathrm{e}}$ can be due to the removal of low-temperature electrons from the plasma due to dissociative electron attachment to the $\mathrm{N}_{2} \mathrm{O}$ molecule, [148] or due to the excitation of the vibrational and rotational levels of the $\mathrm{N}_{2} \mathrm{O}$ molecule, which increases the effective ionization energy of the working gas. [133, 134]

\subsubsection{Mass spectrometry}

The properties of sputtered thin films are strongly dependent on the type and energy of the species arriving at the substrate during film growth. Mass spectrometry can 


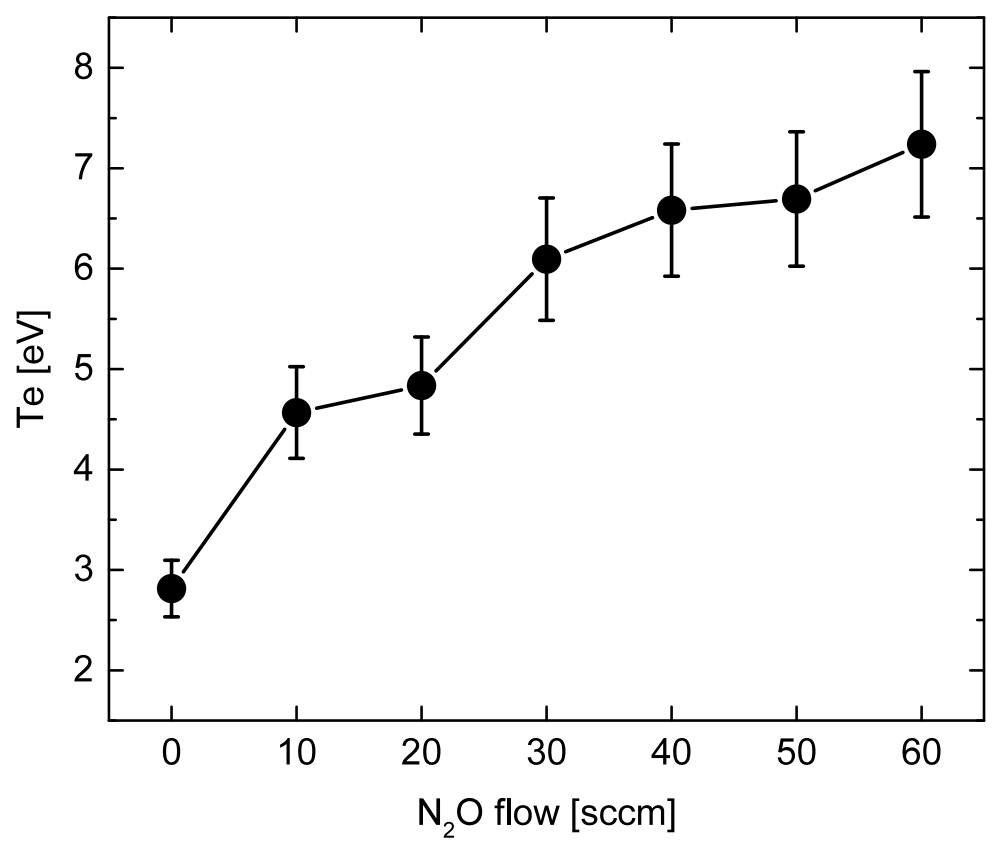

Figure 2.7. The average electron temperature HiPIMS $\mathrm{Ar} / \mathrm{N}_{2} \mathrm{O}$ plasmas measured at the moment of peak target current versus the applied $\mathrm{N}_{2} \mathrm{O}$ flow.

be used to identify these species and to determine their quantity and energy. In the case of pulsed sputtering, also the temporal evolution can be recorded. A mass spectrometer is an instrument consisting of several stages. A probe with an an orifice is immersed in the plasma, in this case inside the sputtering chamber, to collect the species to be analyzed. An ionization stage inside the orifice is used to ionize the neutral species being studied. The ions are then filtered based on their kinetic energies to choose the desired energy range. The remaining ions are further filtered based on their mass-to-charge ratio by using a quadrupole mass filter. Finally the ions are detected by using a secondary electron multiplier, which transforms the counts into an electrical signal. [149]

Mass spectrometry was used in PAPERS III and IV to study the composition and temporal evolution of $\mathrm{Si} / \mathrm{Ar} / \mathrm{N}_{2}$ plasmas, with $\mathrm{N}_{2} /$ Ar flow ratios up to 0.50 . In PAPER III it was observed that increasing $\mathrm{N}_{2} /$ Ar flow ratios resulted in decreasing ion count rates and energies compared to the nonreactive discharge. It was concluded that during pulse on-time the prevailing ion species in the plasma were $\mathrm{Si}^{+}$and $\mathrm{N}^{+} / \mathrm{Si}_{2}{ }^{+}$, where the effect of $\mathrm{Si}_{2}{ }^{+}$to the $\mathrm{N}^{+} / \mathrm{Si}_{2}{ }^{+}$signal was assumed to be low as it was not detected for the nonreactive discharge. The heavier species such as $\mathrm{SiN} / \mathrm{Si}_{2}$ and $2 \mathrm{Ar}$ reached their maximum intensity after the pulse due to their higher probability of collisions and low kinetic energies after forming in the plasma. The difference between these two groups of ions was most pronounced at an $\mathrm{N}_{2} /$ Ar flow ratio of 0.30 . The effect of gas rarefaction was seen in the ${ }^{36} \mathrm{Ar}$ 
signal up to $\mathrm{N}_{2} /$ Ar flows of 0.16 .

In PAPER IV, mass spectrometry was used to investigate the effect of pressure, pulse energy, and target power on the composition and energy distribution of the $\mathrm{Si} / \mathrm{Ar} / \mathrm{N}_{2}$ discharge to connect the plasma properties to residual stresses in the films. Increasing ion energies were observed for lower pressures and larger pulse energies, while increasing pulse frequencies were found to result in larger overall ion count rates.

\subsection{Experimental details of thin film deposition}

An industrial coating unit CC800/9 ML (CemeCon AG, Germany) was used for thin film synthesis and plasma characterization presented in this work. The unit is equipped with six cathodes of which two can be run in either HiPIMS or DC mode and four in either DC or mid-frequency mode. A schematic view of the substrate table and the cathodes is shown in Fig. 2.8. In the case of noncombustible gases Ar and $\mathrm{N}_{2}$ in PAPERS III, IV, and VI, the process gas was let in between the front heater and the closest $\mathrm{DC}$ cathodes. With combustible gases $\mathrm{N}_{2} \mathrm{O}$ and $\mathrm{C}_{2} \mathrm{H}_{2}$, the inlets behind the cathodes on both sides of the chamber were used.

A fixed target-to-substrate distance of $6 \mathrm{~cm}$ was used in all depositions. No substrate rotation was applied in processes studied in PAPERS I-V, while in PAPER VI the substrate table was rotated as multiple targets were used. The applied substrate bias was synchronized with the cathode pulses for thin film deposition in all studies, except in PAPER VI, where a DC bias was used. A constant pulse width of $200 \mu \mathrm{s}$ was applied for the HiPIMS pulses, with frequencies ranging from $100 \mathrm{~Hz}$ to $4000 \mathrm{~Hz}$. The average target power at the Si HiPIMS target ranged between $400 \mathrm{~W}$ and $4000 \mathrm{~W}$. The processes were conducted at substrate temperatures from no applied heating, i.e., only plasma heating, to $530{ }^{\circ} \mathrm{C}$. 


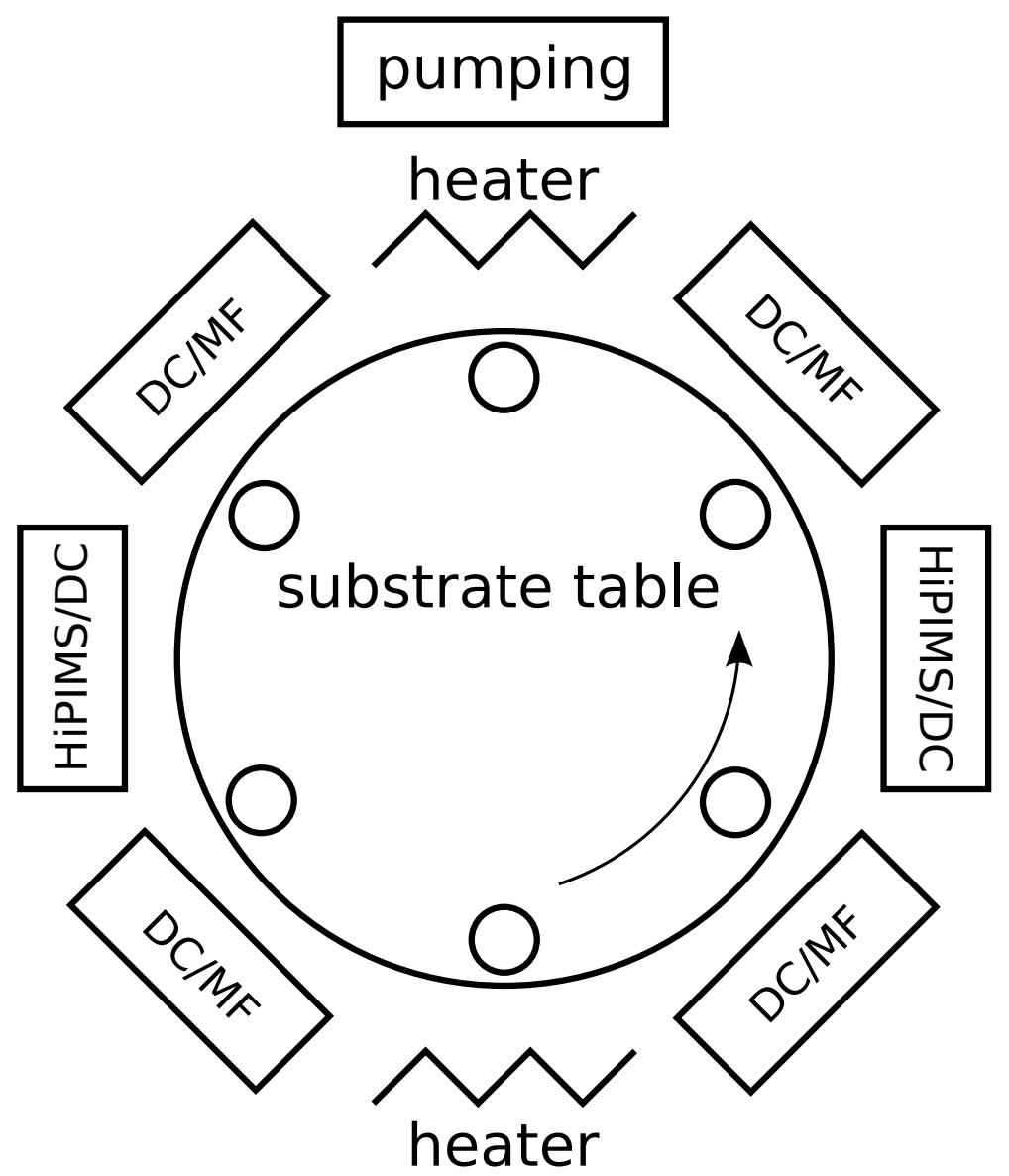

Figure 2.8. A schematic top view of the deposition chamber. 


\section{CHAPTER 3}

\section{Thin film characterization}

Several analysis methods are required to characterize thin film properties. A set of techniques used to determine chemical composition, chemical bonding, mechanical properties, and optical properties of the films are presented in this chapter.

\subsection{X-ray photoelectron spectroscopy}

X-ray photoelectron spectroscopy (XPS) is used to determine both the elemental composition and chemical bonding in the films. The operational principle of XPS is based on the photoelectric effect caused by soft X-rays, commonly $\mathrm{Al} \mathrm{K}_{\alpha}$ radiation $(h \nu=1486.6 \mathrm{eV})$. XPS is a surface sensitive technique, as the inelastic mean free path of photoelectrons is in the order of $\sim 5-10 \mathrm{~nm}$. The measurements have to be performed under ultra-high vacuum conditions to suppress adsorption of residual gas during analysis. [150]

Binding energies $\left(E_{b}\right)$ of the emitted photoelectrons can be determined according to equation (3.1), as their kinetic energies $\left(E_{k}\right)$ are measured and the photon energy $(h \nu)$ is known:

$$
E_{b}=h \nu-E_{k}-\phi,
$$

where $\phi$ is the spectrometer work function. [150]

Both the elemental composition and chemical bonding structure of the sample can be determined by the core level electron binding energies. The detection of hydrogen by XPS is virtually impossible, because it only has one valence electron and no inner electrons. The signal from the $\mathrm{H}$ valence electron would be lost within the signal from all the other valence electrons of the surface atoms in the sample. [151] Different elements have distinct core level binding energies that can be slightly influenced by the chemical environment of the atom, a phenomenon known as the chemical shift. For example, the core level electrons of an atom bonded to a more 
electronegative atom will have a stronger Coulomb interaction with the nucleus, as valence electrons are drawn towards the more electronegative element. Charge compensation can be applied in the case of dielectric samples, such as $\mathrm{SiO}_{\mathrm{x}} \mathrm{N}_{\mathrm{y}}$ films, because charge accumulation on the sample results in a shift of measured binding energies. [150]

The sample surface can be sputter cleaned with an ion beam etch to remove the oxidized surface layer and adventitious carbon occurring on most materials. A significant oxygen surplus in the elemental composition would be observed if the elemental composition was to be determined from this oxidized surface layer. The energetic ions used for the sputter cleaning can, however, damage the chemical bonding structure and alter the composition in some amorphous materials. In such cases the chemical bonding structure can instead be determined from as-received films, without applying sputter cleaning, thus avoiding possible alterations to the chemical bonding structure. [152]

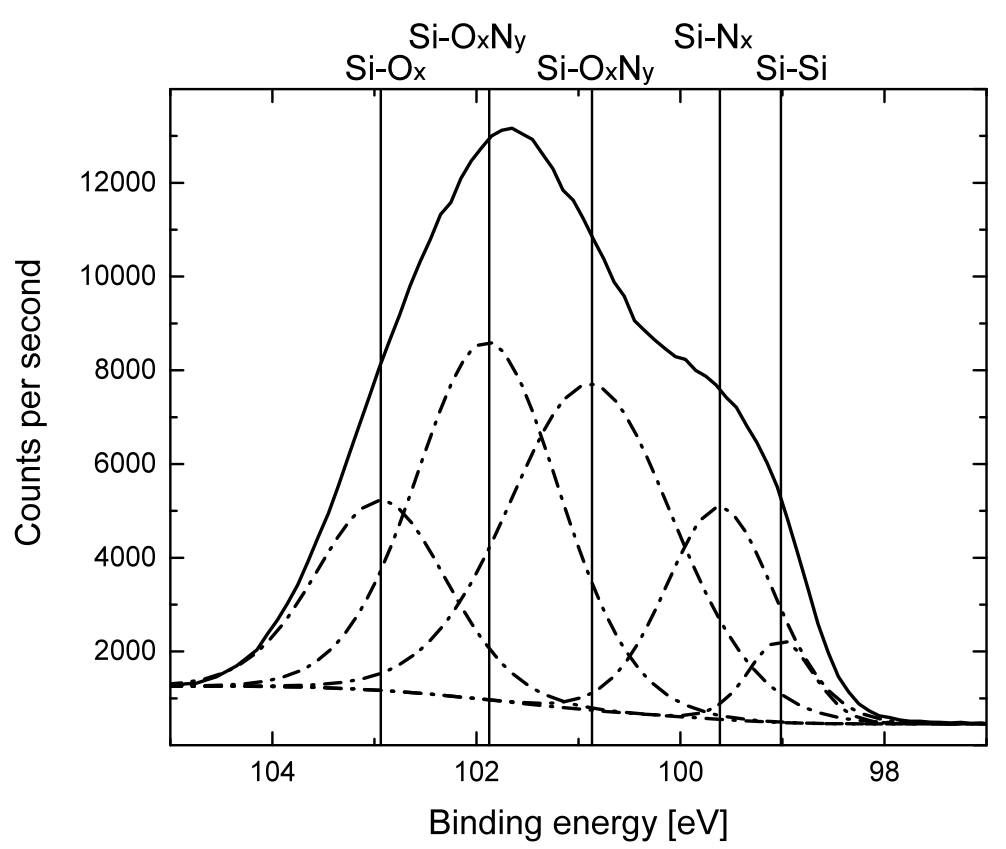

Figure 3.1. A XPS Si 2 p core level spectrum recorded for a $\mathrm{SiO}_{\mathrm{x}} \mathrm{N}_{\mathrm{y}}$ film containing 27 at.\% and 17 at.\% of of $\mathrm{N}$ and $\mathrm{O}$, respectively. Five peaks can be fitted to the spectrum.

A peak fitting procedure has to be implemented to obtain information about the chemical bonding in the films. In compound films, the number of different chemically shifted contributions in the core level spectra of elements partaking in chemical bonding can be up to five, or even more in some cases. [153, 154] An example of a Si $2 p$ core level spectrum obtained before a sputter clean for a $\mathrm{SiO}_{\mathrm{x}} \mathrm{N}_{\mathrm{y}}$ film containing 27 at. $\%$ of $\mathrm{N}$ and 17 at.\% of $\mathrm{O}$, and fitted with a peak fit model consisting of five distinct peaks is shown in Fig. 3.1. Here, the different chemical 
bonding contributions can be assigned to $\mathrm{Si}-\mathrm{Si}$ bonds at $99 \mathrm{eV}, \mathrm{Si}-\mathrm{N}_{\mathrm{x}}$ bonds at $99.7 \mathrm{eV}, \mathrm{Si}-\mathrm{O}_{\mathrm{x}} \mathrm{N}_{\mathrm{y}}$ contributions at $100.9 \mathrm{eV}$ and $101.9 \mathrm{eV}$, and $\mathrm{Si}-\mathrm{O}_{\mathrm{x}}$ bonds at $102.9 \mathrm{eV}$. The $\mathrm{Si}-\mathrm{O}_{\mathrm{x}} \mathrm{N}_{\mathrm{y}}$ contributions have the largest FWHM values, as much as $1.8 \mathrm{eV}$, while for the $\mathrm{Si}-\mathrm{Si}$ bonds the peak FWHM is under $1 \mathrm{eV}$.

In $\mathrm{SiO}_{\mathrm{x}} \mathrm{N}_{\mathrm{y}}$ films, the number of different bonding contributions in the Si $2 \mathrm{p}$ core level spectra depends on the bonding model of the films. In the case of the film shown in Fig. 3.1, deposited at a relatively low temperature $\left(\lesssim 350{ }^{\circ} \mathrm{C}\right)$ by HiPIMS, both $\mathrm{N}$ and $\mathrm{O}$ are randomly distributed in the Si matrix. [153, 154] As silicon can form four bonds, multiple different bonding configurations with varying $x$ and $y$ in $\mathrm{SiO}_{\mathrm{x}} \mathrm{N}_{\mathrm{y}}$ are possible. This results in large peak widths for the components corresponding to $\mathrm{SiO}_{\mathrm{x}} \mathrm{N}_{\mathrm{y}}$ compositions. [153, 154]

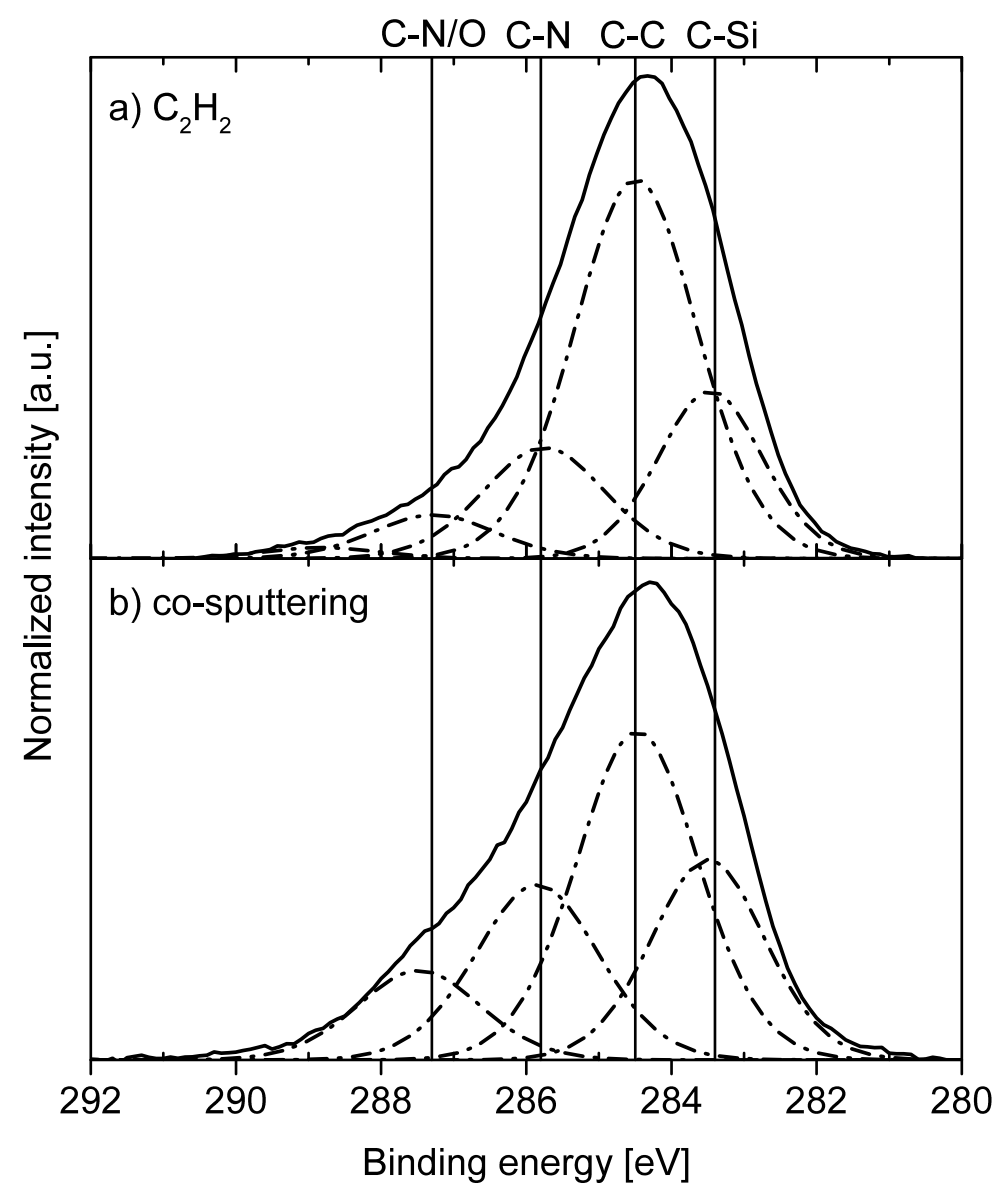

Figure 3.2. The XPS C 1s core level spectra recorded for a SiCN films containing $\sim 20$ at.\% C, a) deposited by using acetylene as the carbon source and b) by co-sputtering from $\mathrm{C}$ and $\mathrm{Si}$ targets.

The bonding of carbon in SiCN films depends on the carbon source, as was 
found out in PAPERS V and VI. As seen in Fig. 3.2 the C 1s core level spectra are slightly different for films co-deposited from $\mathrm{C}$ and $\mathrm{Si}$ targets than films deposited with $\mathrm{C}_{2} \mathrm{H}_{2}$ as the carbon source. Both films contain $\sim 20$ at. $\%$ of $\mathrm{C}$ and 33 at. $\% \mathrm{Si}$, the $\mathrm{N}$ content in the co-sputtered films is higher (43 at.\%) than in the $\mathrm{C}_{2} \mathrm{H}_{2}$ films (29 at.\%) that also contain 14 at.\% hydrogen. In the co-sputtered films the area of the C-Si component $283.4 \mathrm{eV}$ [64] corresponds to $24 \%$ of the total $\mathrm{C} 1 \mathrm{~s}$ peak area, while in the $\mathrm{C}_{2} \mathrm{H}_{2}$ films it amounts for $22 \%$. A larger difference is observed for the $\mathrm{C}-\mathrm{C}$ component at $284.5 \mathrm{ev}$ [155], in the co-sputtered films it amounts for $42 \%$ of the total $\mathrm{C}$ 1s area and for $54 \%$ in $\mathrm{C}_{2} \mathrm{H}_{2}$ films. The co-sputtered films have a higher amount of $\mathrm{C}-\mathrm{N}$ and $\mathrm{C}-\mathrm{N} / \mathrm{O}$ bonded carbon $(34 \%)$, at $285.8 \mathrm{eV}$ and $287.3 \mathrm{eV}$, respectively, than the $\mathrm{C}_{2} \mathrm{H}_{2}$-based films (28\%). The components in the co-sputtered films are also shifted towards higher binding energies by $0.2-0.3 \mathrm{eV}$ when compared to the $\mathrm{C}_{2} \mathrm{H}_{2}$ films as a result of their higher $\mathrm{N}$ content and more electronegative bonding environment.

\subsection{Elastic recoil detection analysis}

Elastic recoil detection analysis (ERDA) is an ion beam analysis method used to obtain thin film sample's elemental concentration depth profiles. In ERDA, high energy ion beam, such as $36 \mathrm{MeV}^{127} \mathrm{I}^{8+}$ used in PAPER I, is collided with the sample and the energies of forward-directed elastic recoils are measured. A time-of-flight (ToF) spectrometer can be used to differentiate between recoils having the same energy but different mass. The use of a ToF spectrometer allows the determination of element depth profiles, as ions originating from below the sample surface lose some of their energy in collisions. [156]

The energy of a target atom with mass $M_{2}$ after an elastic collision with a projectile with mass $M_{1}$ and energy $E_{1}$ is given by equation (3.2):

$$
E_{2}=\frac{4 M_{1} M_{2} \cos ^{2} \theta}{\left(M_{1}+M_{2}\right)^{2}} E_{1}=K_{R} E_{1},
$$

where $\theta$ is the scattering angle and $K_{R}$ is the kinematic factor for elastic recoil. The maximum scattering angle depends on the ratio of the masses of the projectile and the target atom. The maximum scattering angle is given by equation (3.3): [157]

$$
\phi_{\max }=\arcsin \left(\frac{M_{2}}{M_{1}}\right) .
$$

As can be seen from (3.3), the amount of detectable elements for a certain sample depends on the system geometry and the choice of projectile. For film elemental compositions measured in PAPERS I and $\mathrm{V}$ a $36 \mathrm{MeV}{ }^{127} \mathrm{I}^{8+}$ ion beam at an angle of $22.5^{\circ}$ relative to the sample surface was used.

The use of ERDA was necessary to study the elemental composition of the films in PAPER V, deposited with acetylene as the carbon source, since XPS can not be used to detect hydrogen. A concern however associated with ERDA measurements for films of low- $Z$ elements is the possible film alteration due to ion bombardment. [158] As the density of some films in PAPER V was under $2.0 \mathrm{~g} / \mathrm{cm}^{3}$ and the carbon 


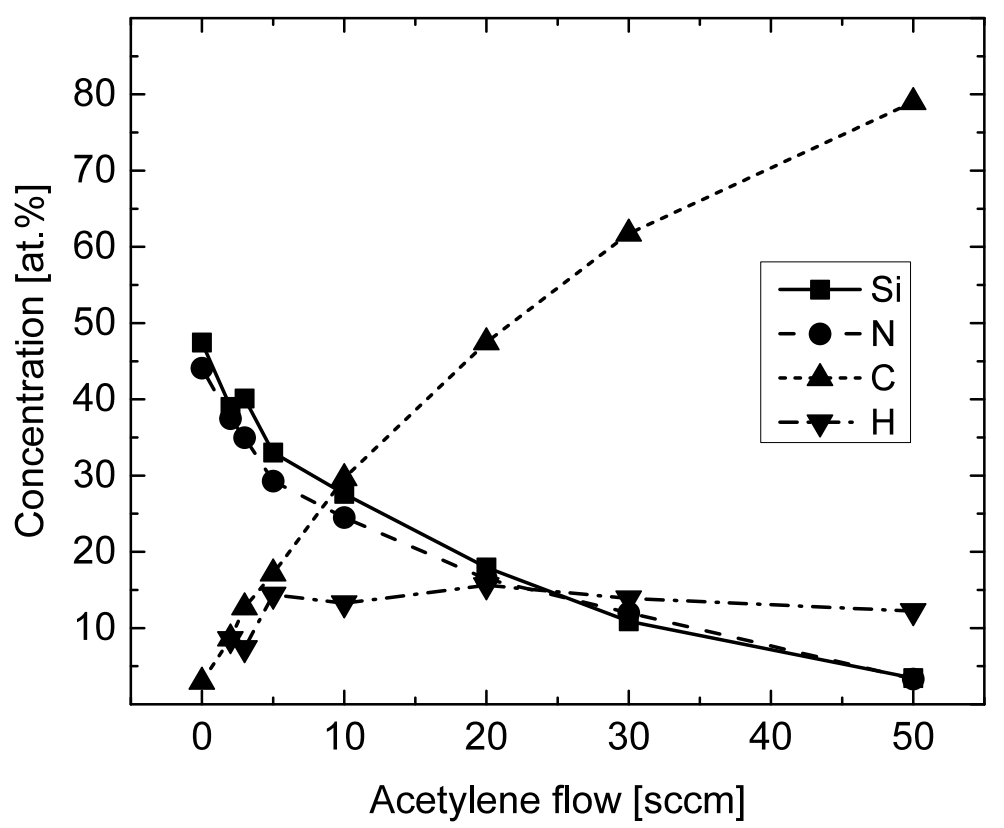

Figure 3.3. The elemental composition $\mathrm{SiCN}: \mathrm{H}$ films versus the applied acetylene flow as measured by ERDA, from PAPER V.

content was expected to be as high as $80 \%$, caution was taken to avoid too long measurement times and potentially causing damage to the samples during the measurement. Figure 3.3 shows the elemental composition of the $\mathrm{SiCN}: \mathrm{H}$ films studied in PAPER $\mathrm{V}$ as a function of the applied $\mathrm{C}_{2} \mathrm{H}_{2}$ flow rate. As expected, the amount of $\mathrm{C}$ increases as the $\mathrm{C}_{2} \mathrm{H}_{2}$ flow rate is increased, and at the same time the $\mathrm{Si}$ concentration decreases. The amount of $\mathrm{N}$ is decreasing with increasing $\mathrm{C}_{2} \mathrm{H}_{2}$ flows as $\mathrm{C}_{2} \mathrm{H}_{2}$ is more readily ionized in the plasma. [105, 106, 139]

The film hydrogen content does not follow a similar pattern, but rather seems to reach a plateau at $\sim 15$ at.\%. Based only on the level of acetylene in the plasma one could expect increasing film $\mathrm{H}$ contents with increasing $\mathrm{C}_{2} \mathrm{H}_{2}$ flows. The potential causes behind the leveling of film $\mathrm{H}$ concentration include removal of $\mathrm{H}$ by ion bombardment either at the target or the growing film during the synthesis, [159-161] or potentially by the beam during the ERD measurement. Further investigations are required to precisely identify the cause behind the leveling of film $\mathrm{H}$ concentration.

\subsection{X-ray reflectivity}

$\mathrm{X}$-ray reflectivity is a technique based on specular reflection of X-rays from surfaces and interfaces. The reflection is based on the different electron densities of the layers. The method can be used to determine thin film thickness, density, surface 
roughness, and multilayer structures in a glancing angle $\theta / 2 \theta$ configuration, where the incident and reflected angle are equal $(\omega=\theta)$. Below the critical angle $\theta_{c}$, the incident beam undergoes total external reflection. For $\theta>\theta_{c}$ the reflected intensity starts to fall due to absorption in the material. A double critical angle can be observed if the film is less dense than the substrate. [162] In this case the $\mathrm{X}$-rays first penetrate the film when the incident angle exceeds the film critical angle and are reflected at the film-substrate interface. Above $\theta_{c}$ the reflections from different interfaces interfere and give rise to interference fringes. The period of the fringes along with the fall in intensity can be used to determine the thickness and roughness of the layers. [163] [164]

For a monolayer film, equation (3.4) can be used to obtain the film thickness:

$$
n \lambda=2 t \sin \theta \sqrt{1+\frac{\eta^{2}-1}{\sin ^{2} \theta}},
$$

where $n$ is an integer, $\lambda$ is the wavelength of incident X-rays, $t$ is the film thickness, and $\eta$ is the film's complex refractive index. To asses properties such as density and surface roughness, the recorded data can be iteratively fitted with a suitable theoretical model of the sample, if the film composition is known. [163]

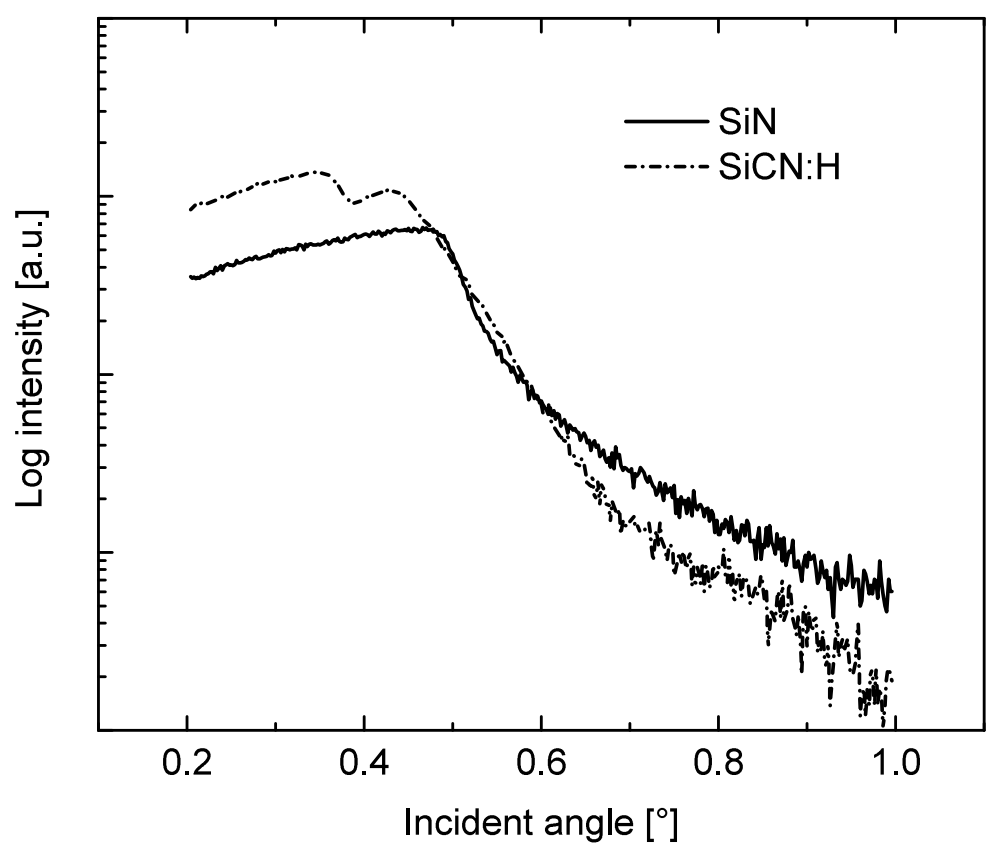

Figure 3.4. Two examples of experimental XRR curves obtained for films studied in PAPER V.

The method was used in PAPERS I, II, III, and V to obtain the film density. Figure 3.4 shows an example of two experimental XRR curves obtained for SiN and SiCN:H films in PAPER V. A clear double critical angle is visible in the $\mathrm{SiCN}: \mathrm{H}$ 
film in the example, containing $\sim 80$ at.\% carbon, due to the film being less dense $\left(1.6 \mathrm{~g} / \mathrm{cm}^{3}\right)$ than the silicon substrate $\left(2.3 \mathrm{~g} / \mathrm{cm}^{3}\right)$. Double critical angles were observed for SiCN:H films containing $\sim 50$ at.\% or more carbon. The experimental XRR curves were fitted with the PANALYTICAL X'PERT REFLECTIVITY software to obtain the film density. A model consisting of the surface oxide layer, the film, and the native oxide on a $\mathrm{Si}$ substrate was used. The densities of co-sputtered SiCN films in PAPER VI could not be resolved reliably by XRR, probably due to the laminate-like structure of the films.

\subsection{Raman spectroscopy}

Raman spectroscopy is a vibrational spectroscopy method commonly used for determining the molecular and lattice vibrations in materials. It is based in the inelastic scattering of monochromatic light, usually from a laser, by the target material, which can be solid, liquid, or even gaseous. Most of the signal consist of light that scatters elastically from the sample, giving rise to a strong signal at the same frequency as the incident light, the so-called Rayleigh scattered light. Some of the photons however interact with the sample molecule or crystal, resulting in a vibrational transition and the frequency of the emitted photon is shifted by the energy required to excite the transition. The Raman spectrum of the sample is made of the inelastically scattered light. The Stokes line corresponds to light with a lower frequency than the incident light, as the target molecule or lattice is excited to a higher vibrational state. In anti-Stokes scattering the sample is on an excited vibrational state and the interaction with the light results in a return to the ground state, and a photon with a larger energy is emitted. The Stokes line is often more pronounced as the sample is in thermodynamic equilibrium. Raman spectroscopy is complementary to infrared spectroscopy and often they are combined to map the vibrational modes of the sample being studied. The Raman scattering requires the molecule or the lattice vibration to have a nonzero change in polarizability upon irradiation, while infrared activity requires a change in dipole moment during vibration. Some of the vibrational modes satisfy both selection rules. The intensity of Raman scattered light is low, only $\sim 10^{-5}$ of the intensity of the incident light, meaning that the signal needs to be filtered to cut off the Rayleigh scattered light. This can be done by using interference filters or by having multiple dispersion stages. [165, 166]

The Raman signal of carbon-containing materials shows characteristic features at $\sim 1360 \mathrm{~cm}^{-1}$ and $\sim 1560 \mathrm{~cm}^{-1}$, named the $D$ and $G$ peaks, respectively. [167] The origin of both $D$ and $G$ peaks is the $s p^{2}$ hybridized carbon. The $G$ peak arises from bond stretching of $s p^{2}$ atoms in rings and chains, while the $D$ peak is due to breathing modes in rings. [168] The shift of peak positions and their relative intensities, the $I(D) / I(G)$ ratio, tell about the ordering of film carbon network. [167] Increasing $I(D) / I(G)$ ratio and decreasing $G$ peak linewidths are signs of ring-like ordering of the $s p^{2}$ carbon network. [168] Raman spectroscopy was used to study the chemical state of carbon in SiCN:H films deposited by HiPIMS in PAPER V. An example of Raman spectra obtained for two films deposited at different 


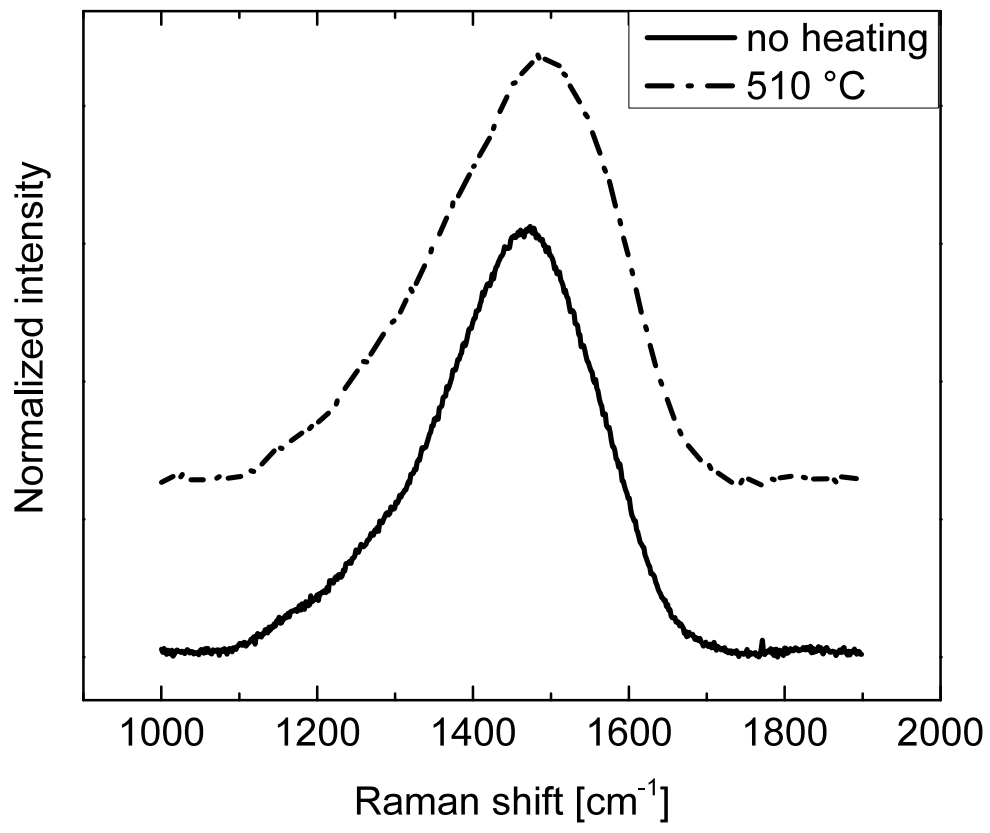

Figure 3.5. Raman spectra of two SiCN:H films deposited at different substrate temperatures by HiPIMS in PAPER V.

substrate temperatures is shown in Fig. 3.5. It was observed that the $G$ peak FWHM decreased from $\sim 200 \mathrm{~cm}^{-1}$ to $\sim 180 \mathrm{~cm}^{-1}$ as substrate temperature was raised from no additional heating to $510{ }^{\circ} \mathrm{C}$. At the same the the $I(D) / I(G)$ ratio rose from 0.44 to 1.10 . Similar ring-like ordering of film $s p^{2}$ carbon network is often seen for carbon-containing thin films as the substrate temperature is increased or after annealing. [169, 170]

\subsection{Transmission electron microscopy}

In transmission electron microscopy (TEM) a beam of electrons is accelerated towards a thin sample. Due to small sample thickness of $\sim 100 \mathrm{~nm}$ part of the electron beam is transmitted through the sample unaffected while some of the beam is scattered by the atoms, either elastically or inelastically. The acceleration voltages used in materials science TEM imaging are usually around $200 \mathrm{kV}$. Magnetic lenses and apertures are used to focus the beam on a desired spot on the sample. Similarly, after the beam passes the sample lenses and apertures are used to select and steer the desired signal to form an image by a CCD camera. The most straightforward TEM imaging mode is the bright field (BF) mode, where only the directly transmitted beam is used to construct the image. In a BF image the sample areas that are thick, have high mass and density appear darker as they scatter more electrons, which are filtered away from the image. The inverse imaging mode 
to $\mathrm{BF}$ is dark field (DF) imaging, where the directly transmitted beam is filtered away and the scattered parts are selected, thus the areas with higher scattering probability appearing brighter in the image. Both signals can be selected to obtain a phase contrast image. Phase contrast imaging is used in high resolution TEM (HRTEM) to achieve atomic resolution.

The electron beam can be used to study the sample structure by means of diffraction, as the diffracted electrons satisfy Bragg's law. The major advantage of using electrons for diffraction studies is their short wavelength compared to $\mathrm{X}$-rays. By selecting a correct aperture a diffraction pattern can be obtained from a certain spot of the sample, creating a selected-area diffraction (SAED) pattern. The SAED pattern can be used to determine the local sample microstructure rather than having the signal from a larger volume as in XRD. For crystalline samples the diffraction pattern consists of discrete dots, while for amorphous samples broad and diffuse rings are observed due to lack of ordering. The distance of the diffraction features from the central spot can be used to calculate the associated lattice spacing.

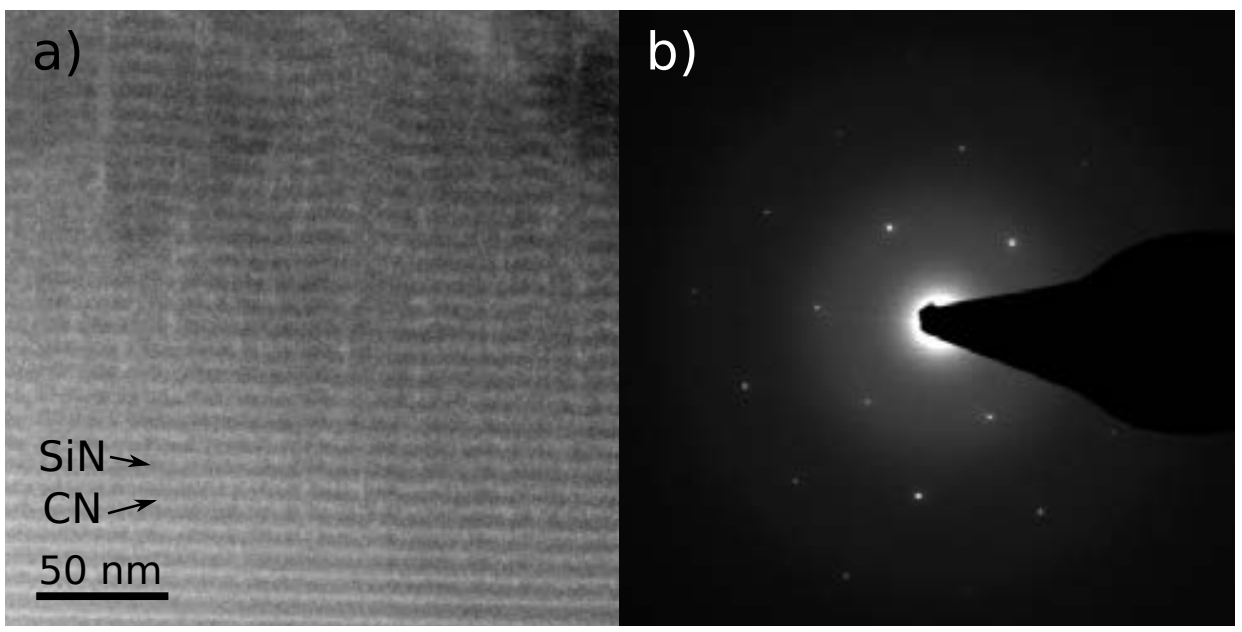

Figure 3.6. a) A TEM image of a layered SiCN film deposited by HiPIMS/DCMS co-sputtering from PAPER VI, b) a SAED pattern from the given SiCN film and the Si substrate.

A multistep preparation procedure needs to be carried out in order to obtain electron transparent cross-sectional TEM samples. For ceramic materials a procedure involving mechanical polishing followed by ion beam thinning is often used, as in PAPER VI. In this procedure, two small pieces of the sample are fitted in a grid with the film sides against each other. The grid is then tightened so that the pieces are firmly secured and glued with a mixture epoxy resin and carbon on a heating plate. After that the sandwich is mechanically polished by using diamond grinding paper to obtain a scratch-free surface and a thickness of under $100 \mu \mathrm{m}$. After the mechanical polishing step the final thinning is done by ion milling. During the ion milling two $\mathrm{Ar}^{+}$ion beams of $1-5 \mathrm{keV}$ at an angle of $\sim 5^{\circ}$ to the surface plane are used to thin the sample. For cross-sectional samples a higher energy of $\sim 5 \mathrm{keV}$ is 
first used to create a hole through the sample and after that the final polishing is carried out at beam energies around $1 \mathrm{keV}$ to clean off the damaged portion of the specimen.

A TEM image of a SiCN film from PAPER VI is shown in Fig. 3.6 a), and its respective SAED pattern along the diffraction pattern of the Si substrate in Fig. 3.6 b). The layered $\mathrm{SiN} / \mathrm{CN}$ structure is clearly visible in the image, the thicker SiN layers appearing darker due to the larger mass of silicon. The SAED pattern gives away the sample's amorphous structure as broad and diffuse rings are observed rather than discrete diffraction spots.

\subsection{Residual stress measurement}

The residual stresses in amorphous thin films can be determined by the wafer curvature method, using X-ray diffraction to obtain the substrate curvature after deposition. An assumption made here is that the residual stresses in the film have only uniform in-plane components, which is a reasonable approximation for amorphous films. [171]

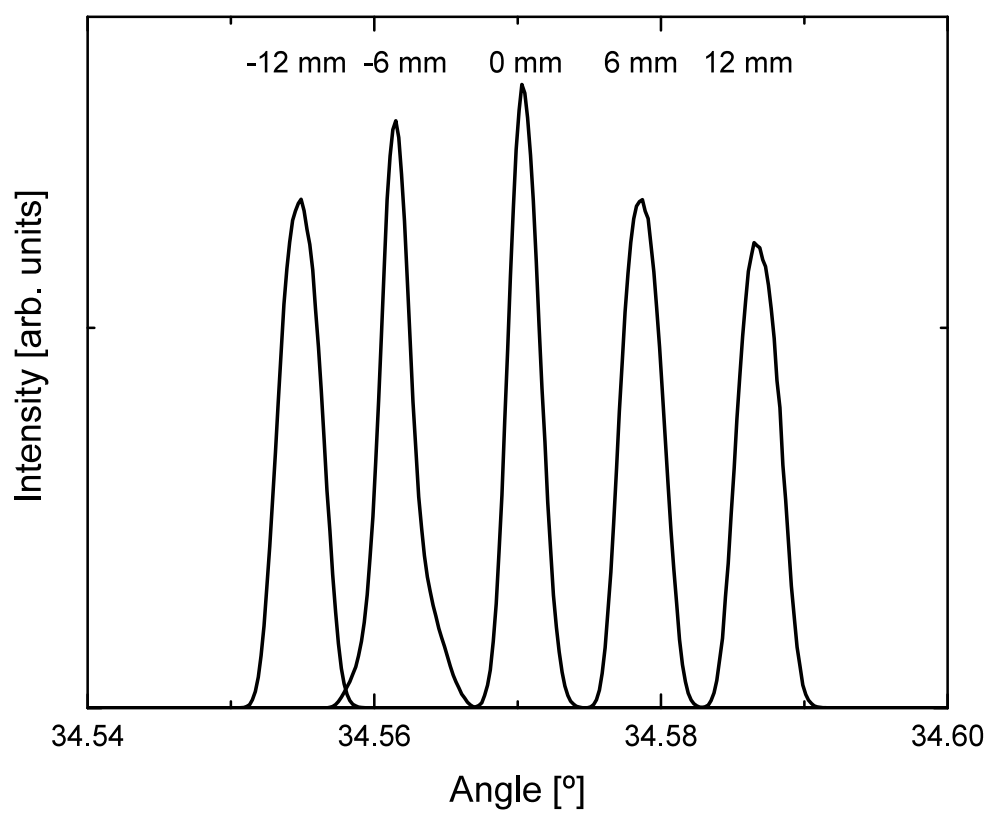

Figure 3.7. A measured shift in the angle between the X-ray beam and the sample surface, while maintaining the $2 \theta$-reflection, versus sample displacement.

The curved crystallographic planes in the stressed silicon substrate cause the angle of diffraction to shift along the rigid translation of the sample. When displacing the sample along the $x$-axis and maintaining the $2 \theta$-reflection, the radius of curvature of the substrate can be determined from the measured shift of the $\omega$-angle (the angle between the beam and the sample surface) as a function of the 
$x$-displacement. A typical measurement for a $\mathrm{SiO}_{\mathrm{x}} \mathrm{N}_{\mathrm{y}}$ film is shown in Fig. 3.8. The specimen curvature is related to the change in orientation of the diffracted beam after displacement in the $x$-axis by equation (3.5): [172]

$$
\frac{1}{R}=\frac{\mathrm{d} \omega}{\mathrm{d} x}
$$

where $R$ is the radius of curvature of the specimen, $\mathrm{d} \omega$ is the change in the orientation of the diffracted beam, and $\mathrm{d} x$ is the sample displacement along the $x$-axis.

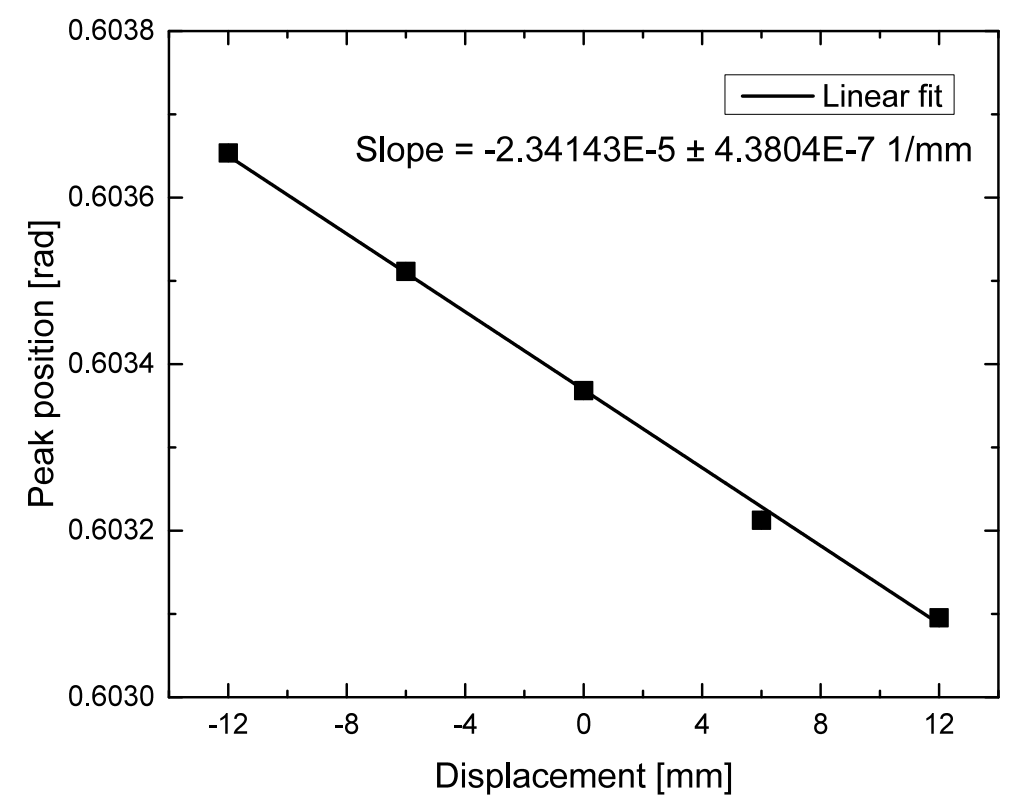

Figure 3.8. A linear fit to the measured displacement-angle pairs to yield the radius of substrate curvature for a $\mathrm{SiO}_{\mathrm{x}} \mathrm{N}_{\mathrm{y}}$ film, from PAPER I.

The effect caused by intrinsic substrate curvature and possible erroneous stage translation can be determined by measuring the curvature of an uncoated substrate. The obtained value is subtracted from the curvature value measured for the coated specimen to obtain the true curvature:

$$
\frac{1}{R}=\frac{\mathrm{d} \omega}{\mathrm{d} x}-\frac{\mathrm{d} \omega}{\mathrm{d} x} \text { uncoated }
$$

The radius of substrate curvature is then given by the slope of $x$-displacement versus the $\omega$-angle in radians, as shown in Fig. 3.8. [172]

The measured substrate curvature can be related to the residual film stress by using the Stoney formula for anisotropic single crystal $\mathrm{Si}(001)$ lattice:

$$
\sigma_{f} t_{f}=\frac{h^{2}}{6\left(s_{11}^{\mathrm{Si}}+s_{12}^{\mathrm{Si}}\right) R},
$$


where $\sigma_{f}$ is the in-plane stress component of the film, $t_{f}$ is the film thickness, $h$ is substrate thickness, and the term $1 /\left(s_{11}^{\mathrm{Si}}+s_{12}^{\mathrm{Si}}\right)$ is the biaxial modulus of $\mathrm{Si}(001)$ $\left(1.803 \cdot 10^{11} \mathrm{~Pa}\right)$. [171, 173] An example of the $\omega$-angle versus sample displacement is shown in Fig. 3.8. With a film thickness of $\sim 420 \mathrm{~nm}$ the residual stress can be calculated to be approximately $-680 \mathrm{MPa}$, indicating compressive residual stress in the film.

\subsection{Nanoindentation}

Nanoindentation is a method commonly used in measuring the hardness and elastic modulus of thin films. In nanoindentation, a sharp diamond tip of known geometry is pressed against the sample surface with a steadily increasing load and then released. The applied load and indentation depth are monitored to construct a load-displacement curve. Typically a Berkovich tip with a three-sided pyramid shape is used to maximize the contact area. In the case of thin films the indentation depth has to be limited to $\sim 10 \%$ of the films thickness, or otherwise the substrate will influence the measurement. The most common method used in analyzing the nanoindentation data is the one suggested by Oliver and Pharr. [174] In the model the load deformation is assumed to be both elastic and plastic, and the unload deformation being only elastic. An example of a load-displacement curve recorded for $\mathrm{SiCN}: \mathrm{H}$ studied in PAPER $\mathrm{V}$ is shown in Fig. 3.9.

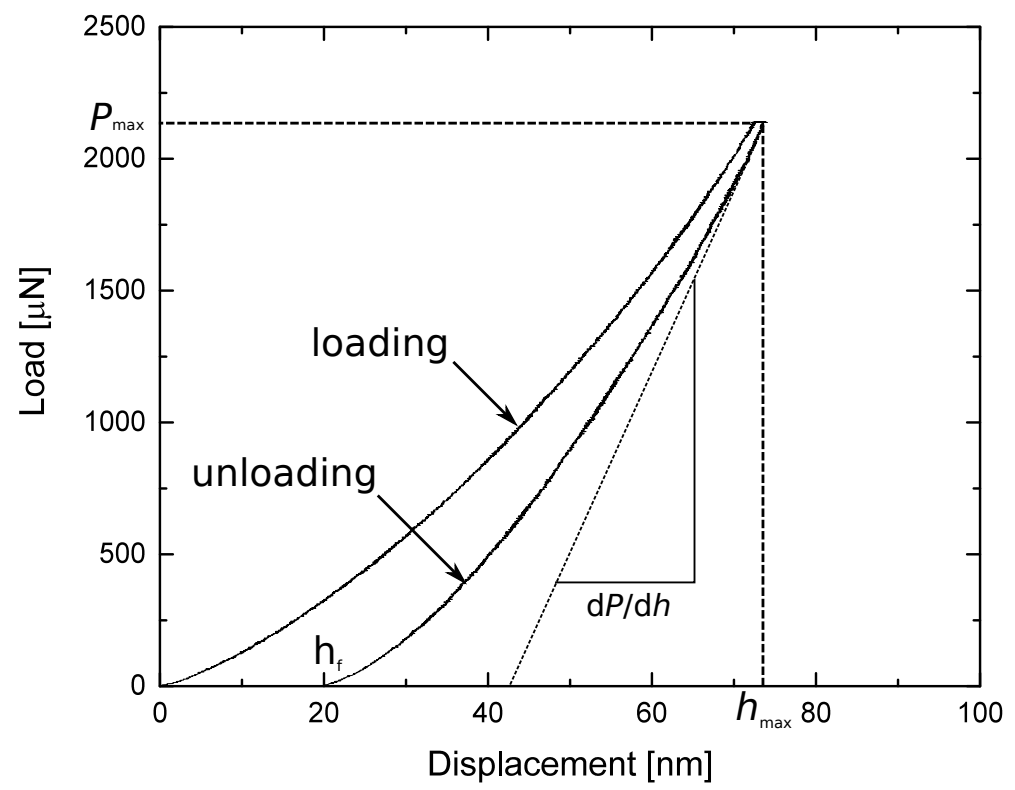

Figure 3.9. A typical load-displacement curve measured for the SiCN:H studied in PAPER V, where $P_{\max }$ is the maximum load, $h_{\max }$ is the maximum displacement, $h_{f}$ is the final displacement, and $\frac{\mathrm{d} P}{\mathrm{~d} h}$ is the elastic unloading stiffness. 
The hardness $(H)$ of the films can be calculated from the effective contact area of the tip $(A)$ and maximum applied load $\left(P_{\max }\right)$ according to equation $(3.8)$ :

$$
H=\frac{P_{\max }}{A} .
$$

The contact area can be estimated by using a tip-specific area function. The required area function on the other hand can be calibrated by performing a series of indents on a sample with a known hardness and elastic modulus, such as fused quartz. [174]

The elastic unloading stiffness $\frac{\mathrm{d} P}{\mathrm{~d} h}$, which can be determined from the tangent of the first part of the unloading curve as shown in Fig. 3.9, and the effective contact area can be connected to the elastic modulus $E$ by using equation (3.9):

$$
\frac{\mathrm{d} P}{\mathrm{~d} h}=\beta \frac{2 E_{\mathrm{e} f f} \sqrt{A}}{\sqrt{\pi}},
$$

where $\beta$ is a tip specific constant ( $\sim 1$ for a Berkovich tip) and $E_{\mathrm{e} f f}$ is the effective elastic modulus. Effective elastic modulus is defined as:

$$
\frac{1}{E_{\mathrm{e} f f}}=\frac{1-\nu^{2}}{E}-\frac{1-\nu_{\mathrm{i}}^{2}}{E_{\mathrm{i}}} .
$$

Here, $\nu$ is the Poisson ratio and of the specimen, $E$ is the elastic modulus of the specimen, $\nu_{\mathrm{i}}$ is the Poisson ratio of the indenter, and $E_{\mathrm{i}}$ is the elastic modulus of the indenter. [174]

Nanoindentation was used in PAPERS III, IV, V, and VI to study the hardness and elastic modulus of SiN and SiCN thin films.

\subsection{Spectroscopic ellipsometry}

Spectroscopic ellipsometry is a technique widely used for structural and optical characterization of thin films and surfaces. In the case of standard ellipsometry, the measured parameters are the ellipsometric angles $\Psi$ and $\Delta$. In reflection mode the state of polarization of light reflected from the sample is analyzed, when the incident light has a known polarization. The complex reflectance ratio $\rho$ between the $p$ and $s$ polarization planes can be linked to the measured angles by equation $(3.11):[175]$

$$
\rho=\frac{r_{p}}{r_{s}}=\tan \Psi \exp i \Delta,
$$

where $r_{p}$ and $r_{s}$ are the complex reflection coefficients for $p$ - and $s$-polarization, respectively.

A dual rotating compensator ellipsometer setup can be used to measure the full Mueller matrix $\mathbf{M}$ of the sample. A Mueller matrix is a $4 \times 4$ matrix describing the polarization properties of an optical element interacting with the incident light. Measuring the Mueller matrix allows determination of depolarization effects, caused by, for example, nonuniform film thickness. A simple schematic of a dual rotating 


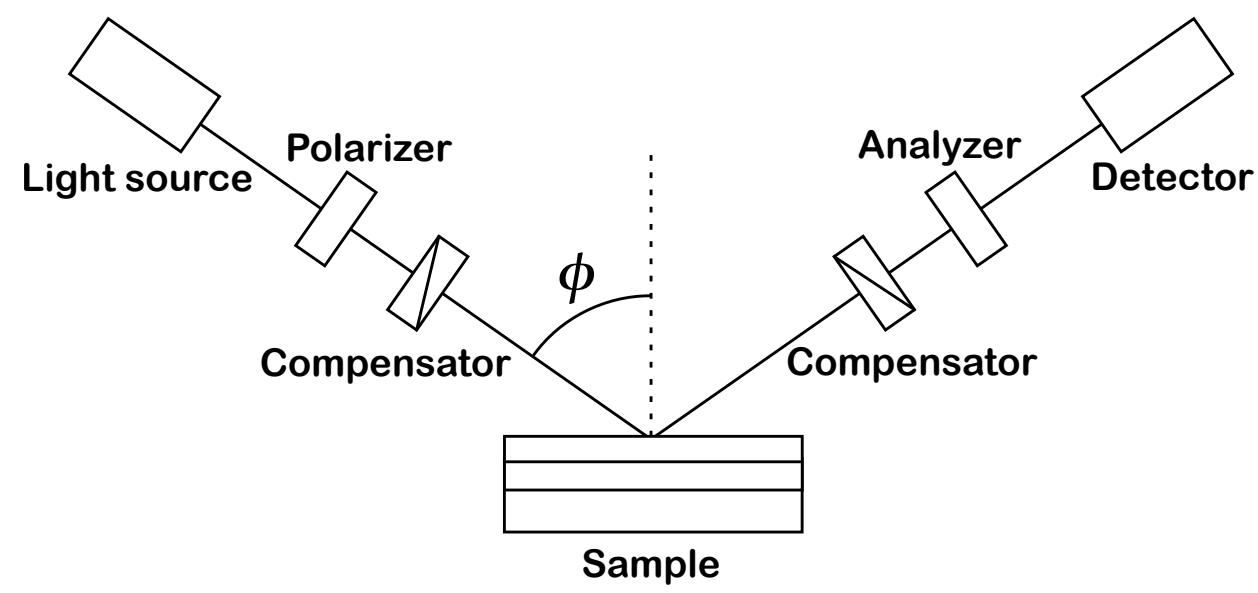

Figure 3.10. A schematic drawing of a dual rotating compensator spectroscopic ellipsometer.

compensator ellipsometer setup is shown in Fig. 3.10. Unpolarized light is passed through a polarizer and a rotating compensator modulating the polarization, before being reflected from the sample. After being reflected, the light passes through a second rotating compensator and an analyzer before being detected. [175]

In the case of isotropic reflecting samples, such as amorphous $\mathrm{SiO}_{\mathrm{x}} \mathrm{N}_{\mathrm{y}}$ films, the number of nonzero elements in $\mathbf{M}$ decreases to 8 and $\mathbf{M}$ takes the following form: $[175]$

$$
\mathbf{M}=\left[\begin{array}{cccc}
1 & -N & 0 & 0 \\
-N & 1 & 0 & 0 \\
0 & 0 & C & S \\
0 & 0 & -S & C
\end{array}\right]
$$

The elements $N, C$, and $S$ can be related to the ellipsometric angles by relations (3.13) a-c:

$$
\begin{aligned}
N & =\cos 2 \Psi, \\
C & =\sin 2 \Psi \cos \Delta, \\
S & =\sin 2 \Psi \sin \Delta .
\end{aligned}
$$

For $N, C$, and $S$ it holds that

$$
N^{2}+C^{2}+S^{2}=1
$$

The $N, C$, and $S$ can also be connected to equation (3.11) by equation (3.14): [175]

$$
\rho=\frac{r_{p}}{r_{s}}=\frac{C+i S}{1+N}=\tan \Psi \exp i \Delta .
$$

In most cases the ellipsometric measurement is indirect, and does not yield the sample's structural properties, but they have to obtained by iteratively fitting 
the data with a suitable model including the possible layers and interfaces in the sample. In the case of amorphous $\mathrm{SiO}_{\mathrm{x}} \mathrm{N}_{\mathrm{y}}$ films, the Tauc-Lorentz (TL) dispersion model was used to model the complex dielectric function $\left(\epsilon=\epsilon_{1}+i \epsilon_{2}\right)$ of the films to obtain their refractive indexes $n$ and extinction coefficients $k$. [176, 177] Both $n$ and $k$ can be calculated from $\epsilon$, as $\epsilon_{1}=N^{2}-k^{2}$ and $\epsilon_{2}=2 n k$. In TL model, $\epsilon_{2}$ has the following expression above the band gap energy:

$$
\epsilon_{2}=\frac{1}{E} \frac{A E_{0} C\left(E-E_{g}\right)^{2}}{\left(E^{2}-E_{0}^{2}\right)^{2}+C^{2} E^{2}}, E>E_{g},
$$

where $E$ is the photon energy, $A$ the peak amplitude, $E_{g}$ is the band gap energy, $E_{0}$ is the peak transition energy, and $C$ is a broadening term. Below the band gap energy $\epsilon_{2}=0$. The real part of the dielectric function, $\epsilon_{1}$, can be calculated from $\epsilon_{2}$ by using Kramers-Kronig integration. [176]

The measure of how well the model fits the measured data is quantified by mean squared error (MSE). The MSE is minimized by iteratively fitting the constructed model to the measured data. However, the smallest MSE does not necessarily implicate that the used model is correct. The model has to yield physically meaningful results for the layer thicknesses, for example. [175]

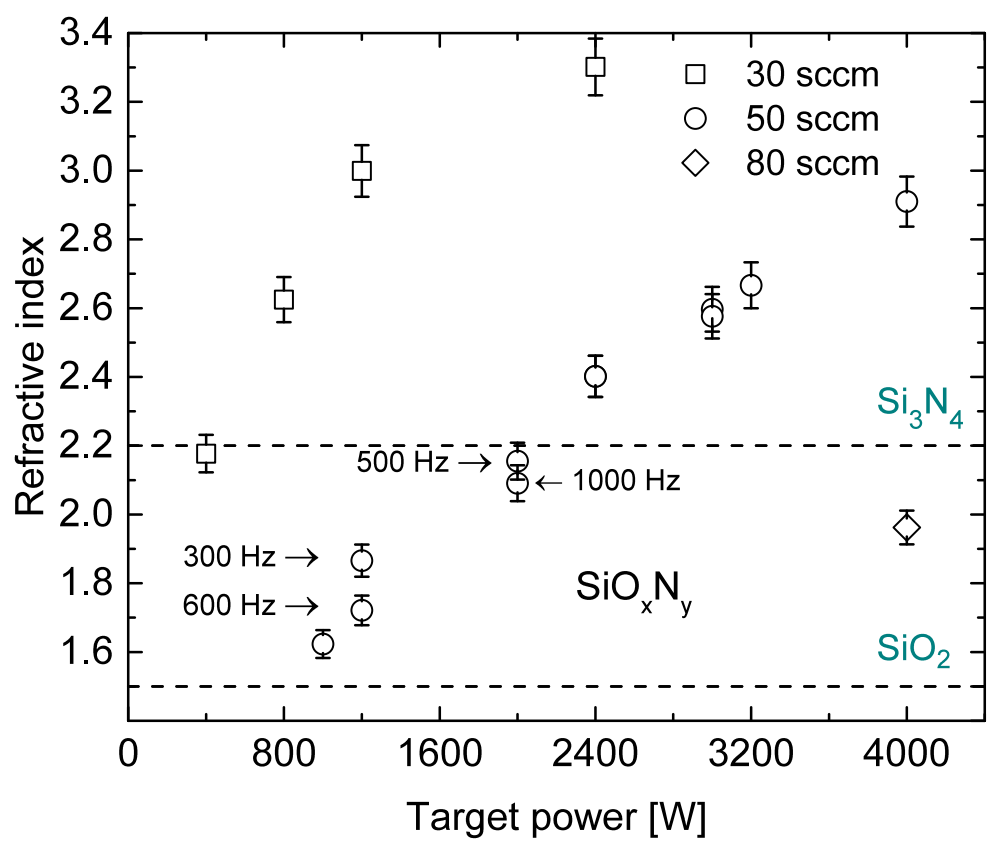

Figure 3.11. Refractive indexes of $\mathrm{SiO}_{\mathrm{x}} \mathrm{N}_{\mathrm{y}}$ films from PAPER II.

Spectroscopic ellipsometry was used in PAPERS I and II to measure the refractive indexes and extinction coefficients of $\mathrm{SiO}_{\mathrm{x}} \mathrm{N}_{\mathrm{y}}$ films. Values ranging between those of silicon nitride and silicon oxide were measured for films were no $\mathrm{Si}-\mathrm{Si}$ bonds 
were detected in the XPS core level spectra. Films with $\mathrm{Si}-\mathrm{Si}$ chemical bonding showed values that were nearing those of amorphous silicon, depending on the film chemical composition. An example of refractive indexes measured for $\mathrm{SiO}_{\mathrm{x}} \mathrm{N}_{\mathrm{y}}$ films versus the applied target power and nitrous oxide flow rate is shown in Fig. 3.11. At low average powers the films show lower values of $n$ due to more oxide-like film chemical composition. Also the pulse frequency affects the $n$, but to lesser extent than the average target power. Higher $\mathrm{N}_{2} \mathrm{O}$ flow rates resulted in lower values due to more stoichiometric film composition. 
CHAPTER 4

\section{Summary of included publications}

\section{Paper I}

A new synthesis route for $\mathrm{SiO}_{\mathrm{x}} \mathrm{N}_{\mathrm{y}}$ thin films by rHiPIMS, using $\mathrm{N}_{2} \mathrm{O}$ as a single-source precursor gas, was presented. The films were characterized based on their chemical, optical, and mechanical properties. The elemental compositions of the films are shown in Fig. 4.1 along with those studied in PAPER II as a ternary plot. The changes in film elemental composition were related to the used deposition parameters through target poisoning. The film elemental composition was controlled by the target power, either by having a fixed pulse energy or increasing the target power, and by the $\mathrm{N}_{2} \mathrm{O}$-to-Ar flow ratio. Increasing $\mathrm{N}_{2} \mathrm{O}$ flow ratios resulted in larger film $\mathrm{O}$ and $\mathrm{N}$ concentrations, while the $\mathrm{O} / \mathrm{N}$ ratio could be controlled by the average target power. The effect of target power was studied both by using a constant energy per pulse and changing the pulse frequency, and by using a fixed pulse frequency and changing the average target power. The $\mathrm{O} / \mathrm{N}$ ratio varied between $0.8-1.9$, while the largest film $\mathrm{O}$ content was $\sim 13$ at.\%. Nitrogen concentrations were not affected by the power settings, but mainly responded to the applied $\mathrm{N}_{2} \mathrm{O}$ flow rate.

Film mechanical properties did not show large variations with respect to deposition parameters. The films showed dense and featureless cross-sections as studied by scanning electron microscopy. Residual stresses from -650 to $-960 \mathrm{MPa}$ were measured, and the average film density was $2.45 \mathrm{~g} / \mathrm{cm}^{3}$.

The film chemical bonding structure was studied by XPS. Increasing $\mathrm{Si}-\mathrm{N}$ and $\mathrm{Si}-\mathrm{O}$ bonding was seen for larger $\mathrm{N}$ and $\mathrm{O}$ contents, respectively. The percentage of $\mathrm{Si}-\mathrm{Si}$ bonding in the spectra was decreasing with increasing $\mathrm{N}_{2} \mathrm{O}$ flows and decreasing target power. Film optical properties were in agreement with the chemical composition. Decreasing values of both $n$ and $k$ were measured for films 


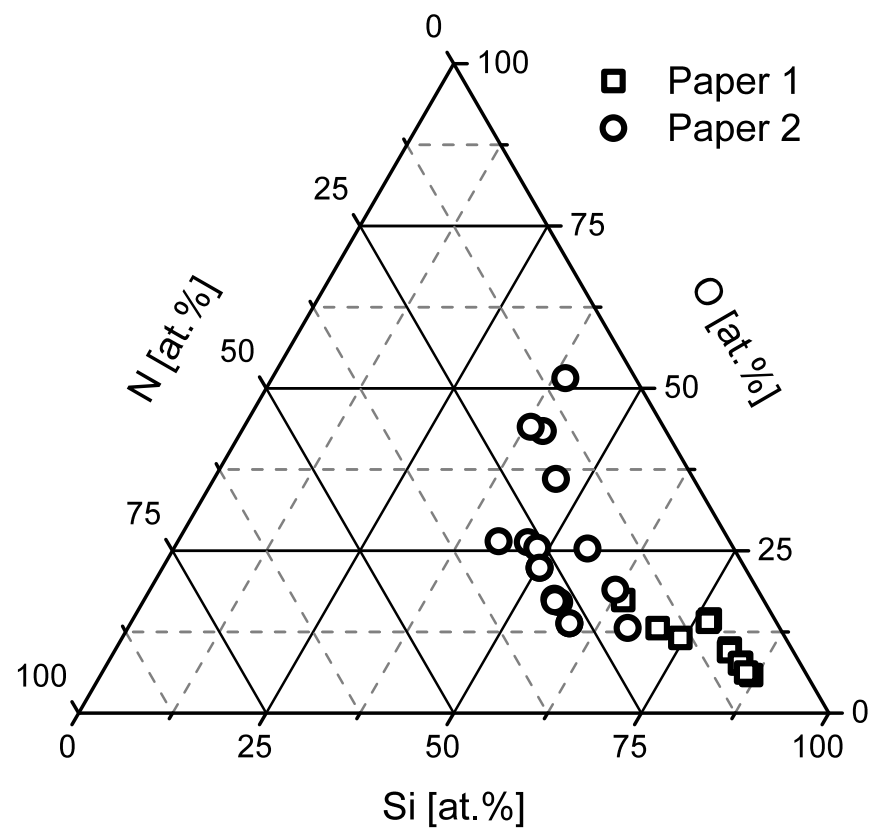

Figure 4.1. The chemical composition of $\mathrm{SiO}_{\mathrm{x}} \mathrm{N}_{\mathrm{y}}$ films studied is PAPERS I and II.

with low silicon contents. The values were still high compared to those measured for stoichiometric silicon oxynitrides $(n<3, k=0)$, with $n$ above 3 and nonzero $k$.

\section{Paper II}

Effectively stoichiometric $\mathrm{SiO}_{\mathrm{x}} \mathrm{N}_{\mathrm{y}}$ thin films, meaning no observable $\mathrm{Si}-\mathrm{Si}$ chemical bonding contributions the XPS Si 2 p spectra, were synthesized by rHiPIMS. The optical properties of these stoichiometric were shown to fall in between those of $\mathrm{SiO}_{2}$ and $\mathrm{Si}_{3} \mathrm{~N}_{4}$. Favorable film deposition conditions were established in the transition and poisoned target surface regimes, based on the analysis of the target current behavior and plasma properties upon the introduction of $\mathrm{N}_{2} \mathrm{O}$. Large $\mathrm{N}_{2} \mathrm{O}$-to-Ar flow ratios were shown to result in mainly $\mathrm{SiO}_{\mathrm{x}}$-like films with low nitrogen concentrations.

The film chemical compositions are shown in Fig. 4.1 As in PAPER I, the film chemical composition was tuned by $\mathrm{N}_{2} \mathrm{O}$ flow rate and the applied power settings. Now, a larger span of different $\mathrm{SiO}_{\mathrm{x}} \mathrm{N}_{\mathrm{y}}$ compositions were covered than in PAPER I, with $x=0.2-1.3, y=0.2-0.7$, due to larger $\mathrm{N}_{2} \mathrm{O}$ flow rates used. The film morphology was dense and featureless, as shown in Fig. 4.2. Film density was found to range between $2.6-3.2 \mathrm{~g} / \mathrm{cm}^{3}$. As in PAPER I, here the film stress did not show correlation with the studied synthesis parameters, but ranged from $-500 \mathrm{MPa}$ to $-1600 \mathrm{MPa}$. 


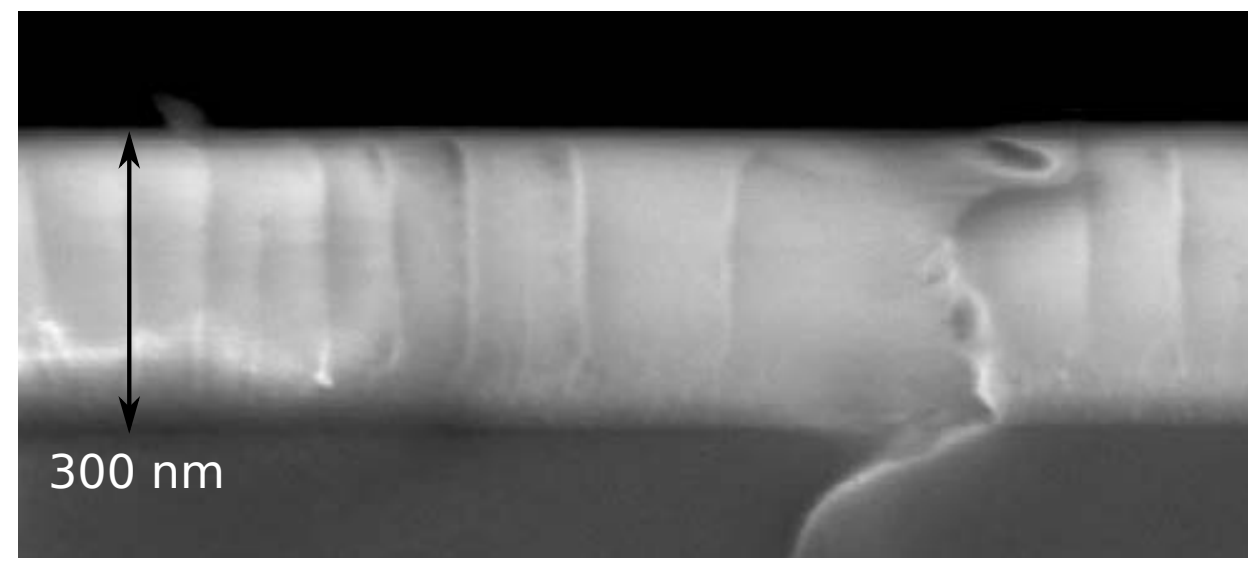

Figure 4.2. A cross-sectional SEM image of a $\mathrm{SiO}_{\mathrm{x}} \mathrm{N}_{\mathrm{y}}$ film, from PAPER II.

\section{Paper III}

Silicon nitride coatings were deposited by rHiPIMS. The influence of $\mathrm{N}_{2}$-toAr flow ratio (from 0 and 0.3), pulse frequency, target power, and substrate temperature on the $\mathrm{SiN}_{\mathrm{x}}$ film nitrogen content was investigated. Mass spectrometry and Langmuir probe analysis were used to characterize the discharge properties. The $\mathrm{N}_{2}$-to-Ar flow ratio was found to be the main factor influencing both the coating properties and the discharge.

Film nitrogen concentrations up to $\sim 50$ at.\% were achieved by using flow ratios of $\sim 0.3$, which corresponds to a discharge operated in the transition region between the metallic and poisoned target surface conditions. These films also showed a high density of $\sim 3 \mathrm{~g} / \mathrm{cm}^{3}$ and a hardness up to $27.5 \mathrm{GPa}$. Average target power had a negligible effect on film nitrogen concentration in the transition mode, whereas under metallic surface conditions an increase in average target power was found to yield larger film silicon contents. Plasma characterization showed increased plasma densities at a $\mathrm{N}_{2}$-to-Ar flow ratio of 0.16 due to dissociation and ionization of $\mathrm{N}_{2}$. In the transition regime at a flow ratio of 0.3 both the plasma density and film growth rate decreased. At the same time the film hardness, elastic modulus, density, and the compressive residual stress increased.

\section{Paper IV}

The paper focused on residual stress in $\mathrm{SiN}_{\mathrm{x}}$ coatings synthesized by rHiPIMS. Depending on the deposition parameters, the coatings showed a wide range of compressive stresses, from $0.2 \mathrm{GPa}$ to $2.1 \mathrm{GPa}$. The main parameters affecting the coating stress were the process pressure, pulse energy, substrate bias, and substrate temperature. The physical mechanisms behind the stress formation were identified as forward sputtering due to energetic ion bombardment, which was 
controlled by process pressure, energy per pulse, and substrate bias. Another contributing factor was ad-atom mobility, evident at low substrate temperatures and increased deposition rates per pulse. Additionally, the difference in thermal expansion coefficients between the film and the substrate caused increasing coating stresses. The parameters that were found to yield coatings with low levels of compressive residual stress and good adhesion (HF1) were a pressure of $600 \mathrm{mPa}$, substrate temperatures below $200{ }^{\circ} \mathrm{C}$, pulse energies lower than $2.5 \mathrm{Ws}$, and negative substrate bias voltages up to $100 \mathrm{~V}$.

\section{Paper V}

Silicon carbonitride films were synthesized by reactive HiPIMS by using silicon targets with acetylene and nitrogen as reactive gases. The characteristics of the deposition process were found to be affected by the applied $\mathrm{C}_{2} \mathrm{H}_{2}$ flow rate. Physical process conditions were identified for $\mathrm{C}_{2} \mathrm{H}_{2}$ flow rates up $10 \mathrm{sccm}$, while higher flow rates resulted in increasingly chemically driven process conditions. The transition between the different regimes was seen as an increasing target current and was noticeable in the film properties. Carbon replaced both $\mathrm{Si}$ and $\mathrm{N}$ equally in the films as more $\mathrm{C}_{2} \mathrm{H}_{2}$ is employed in the process. The films also contained hydrogen, up to 16 at. $\%$, as confirmed by ERDA.

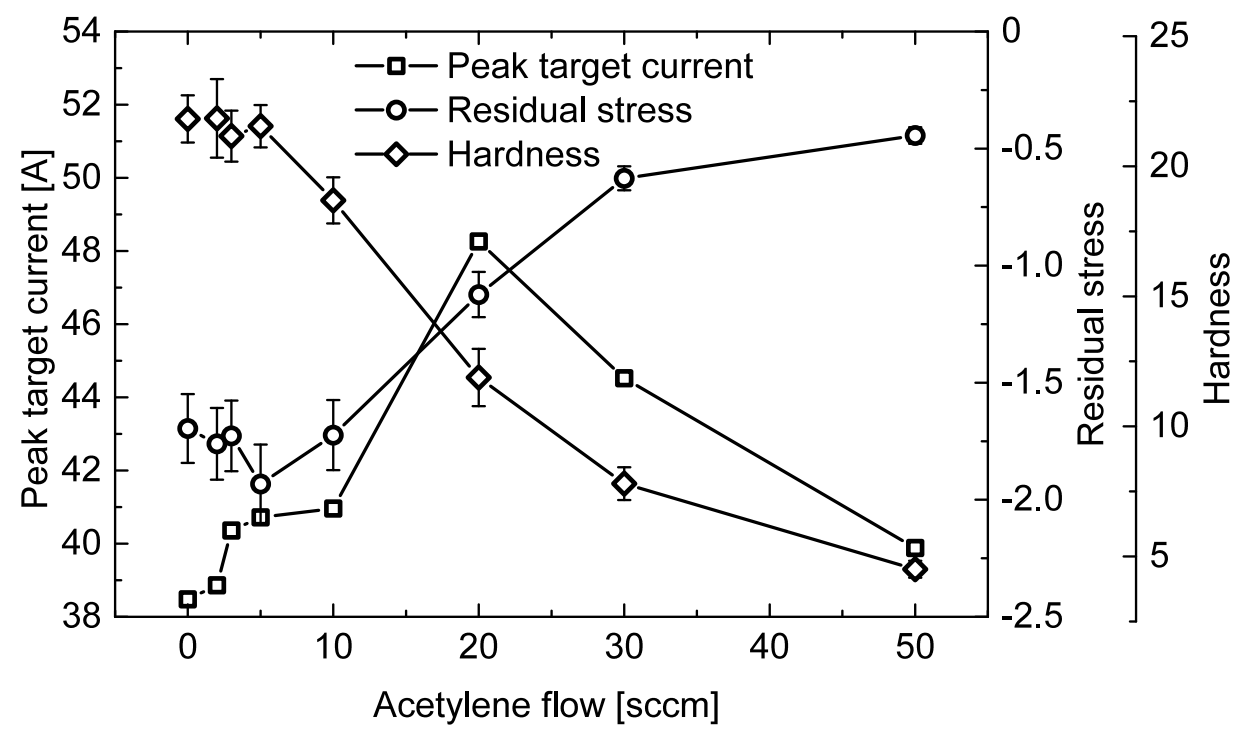

Figure 4.3. The peak target current of the Si target and hardness plus residual stress of $\mathrm{SiCN}$ :H films versus, the applied $\mathrm{C}_{2} \mathrm{H}_{2}$ flow rate, from PAPER $\mathrm{V}$.

The films showed silicon nitride like mechanical properties up to film carbon concentrations of $\sim 20$ at.\%, particularly compressive residual stresses below $1.5 \mathrm{GPa}$ and hardnesses of $21-22$ GPa. Figure 4.3 shows the evolution of the film mechanical properties with the applied $\mathrm{C}_{2} \mathrm{H}_{2}$ flow rate. At $10 \mathrm{sccm}$ the peak target current 
rises sharply and both the residual stress and hardness decrease. The transition was visible in cross-sectional SEM, with film morphologies being increasingly granular as more $\mathrm{C}_{2} \mathrm{H}_{2}$ was used in the process. Film densities decreased accordingly, from $3.0 \mathrm{~g} / \mathrm{cm}^{3}$ measured for the $\operatorname{SiN}_{\mathrm{x}}$ films down to $1.6 \mathrm{~g} / \mathrm{cm}^{3}$ at a film carbon concentration of $\sim 80$ at.\%. Both the substrate temperature and bias affected the film mechanical properties to a lower extent. Both increasing substrate temperatures and bias voltages resulted in larger film stresses and slightly higher hardness.

The chemical bonding in the films was studied with XPS and Raman spectroscopy. Silicon in the films was shown to preferably bond with nitrogen rather than with carbon. Films with carbon contents above 30 at.\% showed no $\mathrm{C}-\mathrm{Si}$ bonding and the $\mathrm{C}$ 1s spectra were close to that of amorphous hydrocarbon. Raman spectroscopy showed that the film carbon bonding network was slightly more ordered in the films deposited at higher substrate temperatures.

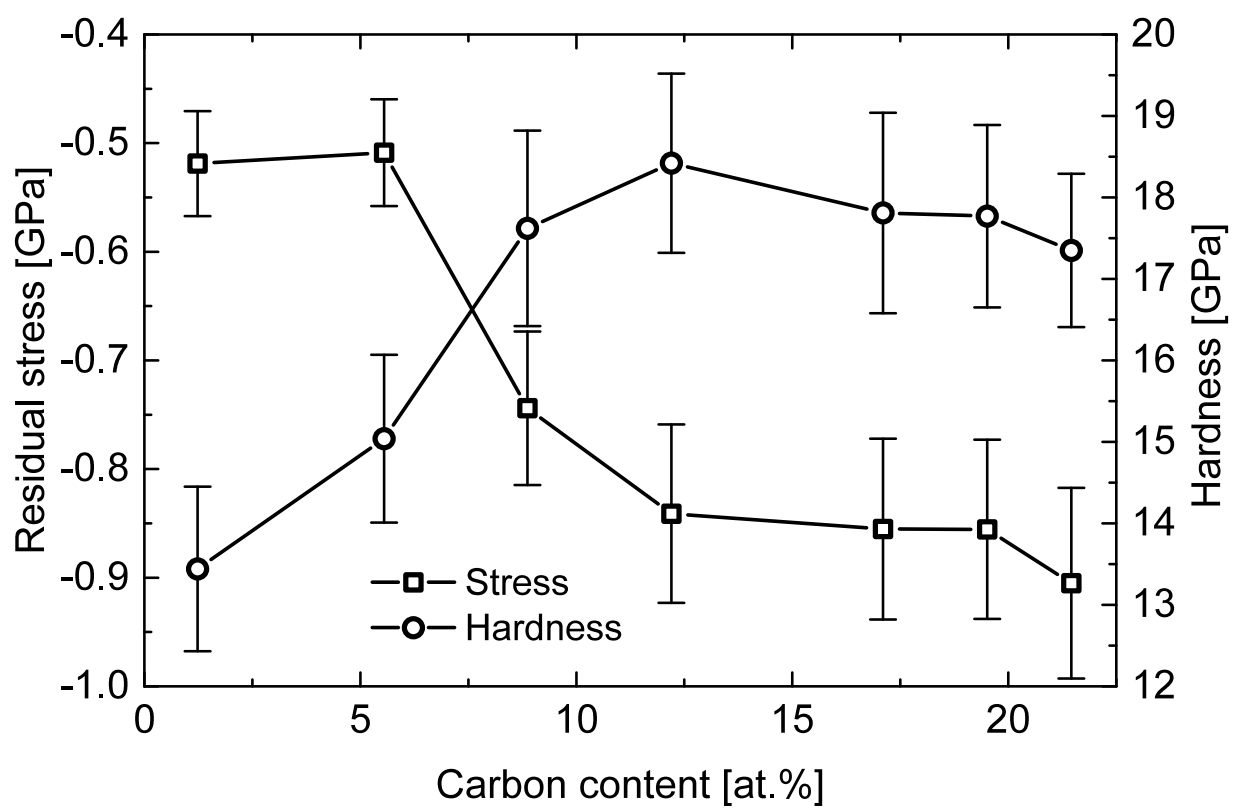

Figure 4.4. The hardness and residual stress of SiCN films as the function of film carbon content, from PAPER VI.

\section{Paper VI}

Silicon carbonitride coatings were deposited by reactive HiPIMS/DCMS cosputtering from elemental Si and $\mathrm{C}$ targets. The films showed columnar morphologies in cross-sectional SEM due to substrate rotation. The composition of the films was controlled through the graphite target power, while the power at $\mathrm{Si}$ targets was fixed. Cross-sectional TEM showed that the films are amorphous. The alternating $\mathrm{SiN}$ and $\mathrm{CN}$ layered structured showed as an increasing $\mathrm{C}-\mathrm{C}$ bonding contribution as the $\mathrm{CN}$ layers grew thicker. Simultaneously the amount of $\mathrm{C}-\mathrm{Si}$ 
bonding decreased.

Improved film mechanical properties were seen when the film carbon content exceeded 9 at.\%, as is seen in Fig. 4.4. Film $H / E$ ratio had a maximum of 0.105 at a $\mathrm{C}$ concentration of 12 at.\%. Increased residual stress and hardness were observed at elevated substrate temperatures and bias voltages. Also a lowered pulse frequency resulted in a slightly increased film hardness. Additionally, a lowered pulse frequency was accompanied by an increased film average surface roughness from $5.4 \mathrm{~nm}$ at $4000 \mathrm{~Hz}$ to $7.8 \mathrm{~nm}$ at $1000 \mathrm{~Hz}$. Parameters that showed the most promise for production of biocompatible SiCN coatings with low surface roughness were a film carbon content of $\sim 12$ at. $\%$, substrate temperatures up to $340{ }^{\circ} \mathrm{C}$, a negative substrate bias up to $100 \mathrm{~V}$, and a large HiPIMS pulse frequency of $3000 \mathrm{~Hz}$ or above. 


\section{Bibliography}

[1] F. L. Riley. "Silicon Nitride and Related Materials". In: Journal of the American Ceramic Society 83.2 (2000), pp. 245-265.

[2] A. Togo and P. Kroll. "First-principles lattice dynamics calculations of the phase boundary between $\beta-\mathrm{Si}_{3} \mathrm{~N}_{4}$ and $\gamma-\mathrm{Si}_{3} \mathrm{~N}_{4}$ at elevated temperatures and pressures". In: Journal of Computational Chemistry 29.13 (2008), pp. 22552259 .

[3] B.S. Bal and M.N. Rahaman. "Orthopedic applications of silicon nitride ceramics". In: Acta Biomaterialia 8.8 (2012), pp. 2889 -2898.

[4] Z. Shi et al. "The structure, surface topography and mechanical properties of Si-C-N films fabricated by RF and DC magnetron sputtering". In: Applied Surface Science 258.4 (2011), pp. $1328-1336$.

[5] M. Pettersson et al. "Mechanical and tribological behavior of silicon nitride and silicon carbon nitride coatings for total joint replacements". In: Journal of the Mechanical Behavior of Biomedical Materials 25 (2013), pp. $41-47$.

[6] M. Pettersson et al. "Structure and composition of silicon nitride and silicon carbon nitride coatings for joint replacements". In: Surface and Coatings Technology 235 (2013), pp. $827-834$.

[7] B.J. McEntire et al. "Ceramics and ceramic coatings in orthopaedics". In: Journal of the European Ceramic Society 35.16 (2015), pp. 4327 -4369.

[8] M. Pettersson et al. "Dissolution behaviour of silicon nitride coatings for joint replacements". In: Materials Science and Engineering: C 62 (2016), pp. $497-505$.

[9] M. Pettersson et al. "Morphology and Dissolution Rate of Wear Debris from Silicon Nitride Coatings". In: ACS Biomaterials Science \& Engineering 2.6 (2016), pp. 998-1004. 
[10] E. Laarz, Boris V. Zhmud, and L. Bergström. "Dissolution and Deagglomeration of Silicon Nitride in Aqueous Medium". In: Journal of the American Ceramic Society 83.10 (2000), pp. 2394-400.

[11] M. Herrmann et al. "Corrosion of silicon nitride materials in acidic and basic solutions and under hydrothermal conditions". In: Journal of the European Ceramic Society 23.4 (2003), pp. $585-594$.

[12] M. Vila, D. Cáceres, and C. Prieto. "Mechanical properties of sputtered silicon nitride thin films". In: Journal of Applied Physics 94.12 (2003), pp. 7868-7873.

[13] J. Olofsson et al. "Fabrication and evaluation of $\mathrm{Si}_{x} \mathrm{~N}_{y}$ coatings for total joint replacements". In: Journal of Materials Science: Materials in Medicine 23.8 (2012), pp. 1879-1889.

[14] J. Tersoff. "Structural properties of $s p^{3}$-bonded hydrogenated amorphous carbon". In: Phys. Rev. B 44 (21 1991), pp. 12039-12042.

[15] F. de Brito Mota, J. F. Justo, and A. Fazzio. "Hydrogen role on the properties of amorphous silicon nitride". In: Journal of Applied Physics 86.4 (1999), pp. 1843-1847.

[16] S. Liu, H. Huang, and Y. T. Gu. "Hardness of silicon nitride thin films characterised by nanoindentation and nanoscratch deconvolution methods". In: Materials Science and Technology 28.9-10 (2012), pp. 1172-1176.

[17] S. Callard, A. Gagnaire, and J. Joseph. "Characterization of graded refractive index silicon oxynitride thin films by spectroscopic ellipsometry". In: Thin Solid Films 313-314.0 (1998), pp. 384-388.

[18] H. Bartzsch et al. "Graded refractive index layer systems for antireflective coatings and rugate filters deposited by reactive pulse magnetron sputtering". In: Surface and Coatings Technology 180-181 (2004), pp. 616-620.

[19] B.S. Sahu et al. "Influence of hydrogen on losses in silicon oxynitride planar optical waveguides". In: Semiconductor Science and Technology 15.3 (2000), p. L11.

[20] C. Gorecki et al. "Characterization of internal stress of silicon oxinitride thin films fabricated by plasma-enhanced chemical vapor deposition: applications in integrated optics". In: Proceedings of SPIE 4596 (2001), pp. 9-15.

[21] S. Arulkumaran et al. "Surface passivation effects on AlGaN/GaN highelectron-mobility transistors with $\mathrm{SiO}_{2}, \mathrm{Si}_{3} \mathrm{~N}_{4}$, and silicon oxynitride". In: Applied Physics Letters 84.4 (2004), pp. 613-615.

[22] J. Dupuis et al. "Impact of PECVD SiON stoichiometry and post-annealing on the silicon surface passivation". In: Thin Solid Films 516.20 (2008), pp. 6954-6958.

[23] R.M. de Ridder et al. "Silicon oxynitride planar waveguiding structures for application in optical communication". In: Selected Topics in Quantum Electronics, IEEE Journal of 4.6 (1998), pp. 930-937. 
[24] M.I. Alayo et al. "Deposition and characterization of silicon oxynitride for integrated optical applications". In: Journal of Non-Crystalline Solids 338-340 (2004), pp. 76-80.

[25] Y. Liu, I.-K. Lin, and X. Zhang. "Mechanical properties of sputtered silicon oxynitride films by nanoindentation". In: Materials Science and Engineering: A 489.1-2 (2008), pp. 294-301.

[26] D. Criado et al. "Study of the mechanical and structural properties of silicon oxynitride films for optical applications". In: Journal of Non-Crystalline Solids 352.23-25 (2006), pp. 2319-2323.

[27] G.J. Wan et al. "Si-N-O Films Synthesized by Plasma Immersion Ion Implantation and Deposition (PIII\&D) for Blood-Contacting Biomedical Applications". In: Plasma Science, IEEE Transactions on 34.4 (2006), pp. 11601165 .

[28] M. Fenker. "Properties of oxynitride thin films for bio-medical applications," in: Metallic Oxynitride Thin Films by Reactive Sputtering and Related Deposition Methods: Processes, Properties and Applications: ed. by F. Vaz, N. Martin, and M. Fenker. Bentham Science Publishers, 2013, pp. 254-264.

[29] K. Wörhoff et al. "Silicon Oxynitride: A Versatile Material for Integrated Optics Applications". In: Journal of The Electrochemical Society 149.8 (2002), F85-F91.

[30] E.C. Samano, J. Camacho, and R. Machorro. "Optimal control on composition and optical properties of silicon oxynitride thin films". In: Journal of Vacuum Science \& Technology A 23.4 (2005), pp. 1228-1233.

[31] C. Ance et al. "Optical absorption in plasma-deposited silicon oxynitride films". In: Applied Physics Letters 60.11 (1992), pp. 1399-1401.

[32] T. Kanata, H. Takakura, and Y. Hamakawa. "Preparation of compositioncontrolled silicon oxynitride films by sputtering; deposition mechanism, and optical and surface properties". In: Applied Physics A 49.3 (1989), pp. 305311.

[33] E. Aubry et al. "Silicon oxynitride thin films synthesised by the reactive gas pulsing process using rectangular pulses". In: Applied Surface Science 257.23 (2011), pp. 10065-10071.

[34] V. Godinho, T.C. Rojas, and A. Fernandez. "Magnetron sputtered a- $\mathrm{SiO}_{x} \mathrm{~N}_{y}$ thin films: A closed porous nanostructure with controlled optical and mechanical properties". In: Microporous and Mesoporous Materials 149.1 (2012), pp. $142-146$.

[35] N. Martin and C. Rousselot. "Instabilities of the reactive sputtering process involving one metallic target and two reactive gases". In: Journal of Vacuum Science \& Technology A 17.5 (1999), pp. 2869-2878.

[36] J. Weber, H. Bartzsch, and P. Frach. "Sputter deposition of silicon oxynitride gradient and multilayer coatings". In: Applied Optics 47.13 (2008), pp. C288C292. 
[37] Y.-N. Xu and W.Y. Ching. "Electronic structure and optical properties of $\alpha$ and $\beta$ phases of silicon nitride, silicon oxynitride, and with comparison to silicon dioxide". In: Physical Review B 51 (1995), pp. 17379-17389.

[38] M.L. Green et al. "Ultrathin $(<4 \mathrm{~nm}) \mathrm{SiO}_{2}$ and $\mathrm{Si}-\mathrm{O}-\mathrm{N}$ gate dielectric layers for silicon microelectronics: Understanding the processing, structure, and physical and electrical limits". In: Journal of Applied Physics 90.5 (2001), pp. 2057-2121.

[39] R. Riedel and I.W. Chen. Ceramics Science and Technology: Volume 1: Structures. Ceramics Science and Technology (VCH). John Wiley \& Sons, 2008 .

[40] V.A. Gritsenko et al. "Short-range order in non-stoichiometric amorphous silicon oxynitride and silicon-rich nitride". In: Journal of Non-Crystalline Solids 297.1 (2002), pp. 96-101.

[41] S. Hasegawa et al. "Structure of defects in silicon oxynitride films". In: Journal of Applied Physics 89.5 (2001), pp. 2598-2605.

[42] F. Rebib et al. " $\mathrm{SiO}_{x} \mathrm{~N}_{y}$ thin films deposited by reactive sputtering: Process study and structural characterisation". In: Thin Solid Films 515.7-8 (2007), pp. 3480-3487.

[43] M. Serényi, M. Rácz, and T. Lohner. "Refractive index of sputtered silicon oxynitride layers for antireflection coating". In: Vacuum 61.2-4 (2001), pp. 245-249.

[44] D.M. Brown et al. "Properties of $\mathrm{Si}_{x} \mathrm{O}_{y} \mathrm{~N}_{z}$ Films on Si". In: Journal of The Electrochemical Society 115.3 (1968), pp. 311-317.

[45] T. Roschuk et al. "Optical and compositional characterization of $\mathrm{SiO}_{x} \mathrm{~N}_{y}$ and $\mathrm{SiO}_{x}$ thin films deposited by electron cyclotron resonance plasma enhanced chemical vapor deposition". In: Journal of Vacuum Science \& Technology A 22.3 (2004), pp. 883-886.

[46] S. Kohli et al. "Spectroscopic ellipsometry and photoluminescence measurements of as-deposited and annealed silicon rich oxynitride films". In: Thin Solid Films 516.12 (2008), pp. 4342-4350.

[47] N. Do et al. "Temperature dependence of optical constants for amorphous silicon". In: Applied Physics Letters 60.18 (1992), pp. 2186-2188.

[48] A. Bender et al. "X-ray reflectivity study of r.f.-sputtered thin $\mathrm{SiO}_{2}$ films". In: Thin Solid Films 229.1 (1993), pp. 29-32.

[49] T. Serikawa and A. Okamoto. "Properties of Magnetron-Sputtered Silicon Nitride Films". In: Journal of The Electrochemical Society 131.12 (1984), pp. 2928-2933.

[50] R. Ctvrtlik et al. "Mechanical Properties and Microstructural Characterization of Amorphous $\mathrm{SiC}_{x} \mathrm{~N}_{y}$ Thin Films After Annealing Beyond 1100 'C". In: Journal of the American Ceramic Society 99.3 (2016), pp. 996-1005. 
[51] P. Jedrzejowski et al. "Mechanical and optical properties of hard SiCN coatings prepared by PECVD". In: Thin Solid Films 447-448 (2004), pp. 201 -207 .

[52] K.B. Sundaram and J. Alizadeh. "Deposition and optical studies of silicon carbide nitride thin films". In: Thin Solid Films 370.1 (2000), pp. $151-154$.

[53] Z. Shi et al. "Microstructure, mechanical properties and wetting behavior of $\mathrm{F}: \mathrm{Si}-\mathrm{C}-\mathrm{N}$ films as bio-mechanical coating grown by DC unbalanced magnetron sputtering". In: Journal of Alloys and Compounds 552.Supplement C (2013), pp. $111-118$.

[54] Y. Iwamoto et al. "Crystallization Behavior of Amorphous Silicon Carbonitride Ceramics Derived from Organometallic Precursors". In: Journal of the American Ceramic Society 84.10 (2001), pp. 2170-2178.

[55] L. Bharadwaj et al. "Oxidation Behavior of a Fully Dense Polymer-Derived Amorphous Silicon Carbonitride Ceramic". In: Journal of the American Ceramic Society 87.3 (2004), pp. 483-486.

[56] C.W. Chen et al. "The affinity of $\mathrm{Si}-\mathrm{N}$ and $\mathrm{Si}-\mathrm{C}$ bonding in amorphous silicon carbon nitride (a-SiCN) thin film". In: Diamond and Related Materials 14.3-7 (2005), pp. $1126-1130$.

[57] K.B Sundaram et al. "Investigations on hardness of rf sputter deposited SiCN thin films". In: Materials Science and Engineering: A 368.1-2 (2004), pp. $103-108$.

[58] H. Hoche et al. "Properties of SiCN coatings for high temperature applications - Comparison of RF-, DC- and HPPMS-sputtering". In: Surface and Coatings Technology 205, Supplement 1 (2010), S21 -S27.

[59] C. Pusch et al. "Influence of the PVD sputtering method on structural characteristics of SiCN-coatings - Comparison of RF, DC and HiPIMS sputtering and target configurations". In: Surface and Coatings Technology 205, Supplement 2 (2011), S119-S123.

[60] X.C Wu et al. "SiCN thin film prepared at room temperature by r.f. reactive sputtering". In: Applied Surface Science 185.3-4 (2002), pp. 262 -266.

[61] H. Hoche et al. "Relationship of chemical and structural properties with the tribological behavior of sputtered SiCN films". In: Surface and Coatings Technology 202.22-23 (2008), pp. $5567-5571$.

[62] A. Badzian et al. "Silicon carbonitride: a rival to cubic boron nitride". In: Diamond and Related Materials 7.10 (1998), pp. 1519 -1525.

[63] A. Badzian. "Stability of Silicon Carbonitride Phases". In: Journal of the American Ceramic Society 85.1 (2002), pp. 16-20.

[64] T. Berlind et al. "Microstructure, mechanical properties, and wetting behavior of $\mathrm{Si}-\mathrm{C}-\mathrm{N}$ thin films grown by reactive magnetron sputtering". In: Surface and Coatings Technology 141.2-3 (2001), pp. $145-155$. 
[65] Y. Peng et al. "Influence of radiofrequency power on compositional, structural and optical properties of amorphous silicon carbonitride films". In: Applied Surface Science 256.7 (2010), pp. $2189-2192$.

[66] S. Guruvenket et al. "Atmospheric Pressure Plasma CVD of Amorphous Hydrogenated Silicon Carbonitride (a-SiCN:H) Films Using Triethylsilane and Nitrogen". In: Plasma Processes and Polymers 8.12 (2011), pp. 11261136 .

[67] D. Bielinski, A. M. Wrobel, and A. Walkiewicz-Pietrzykowska. "Mechanical and Tribological Properties of Thin Remote Microwave Plasma CVD aSi:N:C Films from a Single-Source Precursor". In: Tribology Letters 13.2 (2002), pp. 71-76.

[68] N. I. Fainer and A. A. Nemkova. "Optical properties of silicon carbonitride films produced by plasma-induced decomposition of organic silicon compounds". In: High Energy Chemistry 49.4 (2015), pp. 273-281.

[69] M. Ohring. Materials Science of Thin Films. Burlington, MA, USA: Academic Press, 2001.

[70] D. Lundin and K. Sarakinos. "An introduction to thin film processing using high-power impulse magnetron sputtering". In: Journal of Materials Research 27 (2012), pp. 780-792.

[71] D.M. Mattox. Handbook of Physical Vapor Deposition (PVD) Processing. Elsevier Science, 2010.

[72] K. Wasa. Handbook of Sputter Deposition Technology: Fundamentals and Applications for Functional Thin Films, Nano-materials and MEMS. William Andrew, 2012.

[73] D.M. Mattox et al. "Technical note: Design and performance of a movable post-cathode magnetron sputtering system for making PBFA II accelerator ion sources". In: Surface and Coatings Technology 33.0 (1987), pp. 425-432.

[74] W.D. Gill and E. Kay. "Efficient Low Pressure Sputtering in a Large Inverted Magnetron Suitable for Film Synthesis". In: Review of Scientific Instruments 36.3 (1965), pp. 277-282.

[75] V. Kouznetsov et al. "A novel pulsed magnetron sputter technique utilizing very high target power densities". In: Surface and Coatings Technology 122.2-3 (1999), pp. 290-293.

[76] K. Sarakinos, J. Alami, and S. Konstantinidis. "High power pulsed magnetron sputtering: A review on scientific and engineering state of the art". In: Surface and Coatings Technology 204.11 (2010), pp. 1661-1684.

[77] A. Anders. "Discharge physics of high power impulse magnetron sputtering". In: Surface and Coatings Technology 205, Supplement 2.0 (2011), S1-S9.

[78] J.T. Gudmundsson et al. "High power impulse magnetron sputtering discharge". In: Journal of Vacuum Science \& Technology A 30.3, 030801 (2012). 
[79] J.T. Gudmundsson, J. Alami, and U. Helmersson. "Spatial and temporal behavior of the plasma parameters in a pulsed magnetron discharge". In: Surface and Coatings Technology 161.2-3 (2002), pp. 249-256.

[80] G. Greczynski et al. "Microstructure control of $\mathrm{CrN}_{x}$ films during high power impulse magnetron sputtering". In: Surface and Coatings Technology 205.1 (2010), pp. 118-130.

[81] M. Samuelsson et al. "On the film density using high power impulse magnetron sputtering". In: Surface and Coatings Technology 205.2 (2010), pp. 591-596.

[82] H. Högberg et al. "Reactive sputtering of $\delta-\mathrm{ZrH}_{2}$ thin films by high power impulse magnetron sputtering and direct current magnetron sputtering". In: Journal of Vacuum Science \& Technology A 32.4, 041510 (2014).

[83] J. Alami et al. "Ion-assisted physical vapor deposition for enhanced film properties on nonflat surfaces". In: Journal of Vacuum Science \& Technology A 23.2 (2005), pp. 278-280.

[84] J. Böhlmark et al. "Guiding the deposition flux in an ionized magnetron discharge". In: Thin Solid Films 515.4 (2006), pp. 1928-1931.

[85] A.P. Ehiasarian et al. "High power pulsed magnetron sputtered $\mathrm{CrN}_{x}$ films". In: Surface and Coatings Technology 163-164.0 (2003), pp. 267-272.

[86] A.P. Ehiasarian et al. "Comparison of microstructure and mechanical properties of chromium nitride-based coatings deposited by high power impulse magnetron sputtering and by the combined steered cathodic arc/unbalanced magnetron technique". In: Thin Solid Films 457.2 (2004), pp. 270-277.

[87] J. Alami et al. "On the relationship between the peak target current and the morphology of chromium nitride thin films deposited by reactive high power pulsed magnetron sputtering". In: Journal of Physics D: Applied Physics 42.1 (2009), p. 015304.

[88] R.C. Munoz et al. "Surface-induced resistivity of thin metallic films bounded by a rough fractal surface". In: Physical Review B 66 (2002), p. 205401.

[89] U. Helmersson et al. "Ionized physical vapor deposition (IPVD): A review of technology and applications". In: Thin Solid Films 513.1-2 (2006), pp. 1-24.

[90] J. Vlček et al. "Process stabilization and a significant enhancement of the deposition rate in reactive high-power impulse magnetron sputtering of $\mathrm{ZrO}_{2}$ and $\mathrm{Ta}_{2} \mathrm{O}_{5}$ films". In: Surface and Coatings Technology 236 (2013), pp. $550-556$.

[91] J. Emmerlich et al. "The physical reason for the apparently low deposition rate during high-power pulsed magnetron sputtering". In: Vacuum 82.8 (2008), pp. 867-870.

[92] S. Konstantinidis et al. "Transport of ionized metal atoms in high-power pulsed magnetron discharges assisted by inductively coupled plasma". In: Applied Physics Letters 88.2, 021501 (2006). 
[93] D.J. Christie. "Target material pathways model for high power pulsed magnetron sputteringa)". In: Journal of Vacuum Science \& Technology A 23.2 (2005), pp. 330-335.

[94] G. Greczynski et al. "Role of $\mathrm{Ti}^{n+}$ and $\mathrm{Al}^{n+}$ ion irradiation $(n=1,2)$ during $\mathrm{Ti}_{1-x} \mathrm{Al}_{x} \mathrm{~N}$ alloy film growth in a hybrid HIPIMS/magnetron mode". In: Surface and Coatings Technology 206.19-20 (2012), pp. 4202-4211.

[95] D. Depla and R. De Gryse. "Target poisoning during reactive magnetron sputtering: Part I: the influence of ion implantation". In: Surface and Coatings Technology 183.2-3 (2004), pp. 184-189.

[96] D. Depla and R. De Gryse. "Target poisoning during reactive magnetron sputtering: Part II: the influence of chemisorption and gettering". In: Surface and Coatings Technology 183.2-3 (2004), pp. 190-195.

[97] S. Berg et al. "Process modeling of reactive sputtering". In: Journal of Vacuum Science \& Technology A 7.3 (1989), pp. 1225-1229.

[98] D. Depla et al. "Understanding the discharge voltage behavior during reactive sputtering of oxides". In: Journal of Applied Physics 101.1, 013301 (2007).

[99] D. Depla, S. Mahieu, and R. De Gryse. "Magnetron sputter deposition: Linking discharge voltage with target properties". In: Thin Solid Films 517.9 (2009), pp. 2825-2839.

[100] R.A. Baragiola et al. "Ion-induced electron emission from clean metals". In: Surface Science 90.2 (1979), pp. 240-255.

[101] S. Berg and T. Nyberg. "Fundamental understanding and modeling of reactive sputtering processes". In: Thin Solid Films 476.2 (2005), pp. 215 -230 .

[102] E. Wallin and U. Helmersson. "Hysteresis-free reactive high power impulse magnetron sputtering". In: Thin Solid Films 516.18 (2008), pp. 6398-6401.

[103] M. Hála et al. "Hysteresis-free deposition of niobium oxide films by HiPIMS using different pulse management strategies". In: Journal of Physics D: Applied Physics 45.5, 055204 (2012).

[104] K. Sarakinos et al. "Process stabilization and enhancement of deposition rate during reactive high power pulsed magnetron sputtering of zirconium oxide". In: Surface and Coatings Technology 202.20 (2008), pp. 5033-5035.

[105] G.G. Raju. Gaseous Electronics: Tables, Atoms, and Molecules. Taylor \& Francis, 2012.

[106] H. C. Straub et al. "Absolute partial cross sections for electron-impact ionization of $\mathrm{H}_{2}, \mathrm{~N}_{2}$, and $\mathrm{O}_{2}$ from threshold to 1000 eV". In: Phys. Rev. A 54 (1996), pp. 2146-2153.

[107] R. Locht et al. "The dissociative ionization of nitrogen". In: Chemical Physics 7.3 (1975), pp. $393-404$.

[108] D. C. Frost and C. A. McDowell. "The dissociation energy of the nitrogen molecule". In: Proceedings of the Royal Society of London A: Mathematical, Physical and Engineering Sciences 236.1205 (1956), pp. 278-284. 
[109] K.S. Fancey. "An investigation into dissociative mechanisms in nitrogenous glow discharges by optical emission spectroscopy". In: Vacuum 46.7 (1995), pp. $695-700$.

[110] Nagai, J. et al. "Experimental evidence of Penning ionization role in a low pressure direct current nitrogen glow discharge". In: Eur. Phys. J. Appl. Phys. 26.1 (2004), pp. 53-58.

[111] J. T. Gudmundsson et al. "Are the argon metastables important in high power impulse magnetron sputtering discharges?" In: Physics of Plasmas 22.11 (2015), p. 113508.

[112] D. Depla et al. "Target voltage behaviour during DC sputtering of silicon in an argon/nitrogen mixture". In: Vacuum 66.1 (2002), pp. 9 -17.

[113] F.I. Allen et al. "Transport of multiply and highly charged ions through nanoscale apertures in silicon nitride membranes". In: Nuclear Instruments and Methods in Physics Research Section B: Beam Interactions with Materials and Atoms 244.2 (2006), pp. $323-326$.

[114] A. Novikov. "Experimental measurement of work function in doped silicon surfaces". In: Solid-State Electronics 54.1 (2010), pp. 8 -13.

[115] R. C. Wetzel et al. "Absolute cross sections for electron-impact ionization of the rare-gas atoms by the fast-neutral-beam method". In: Phys. Rev. A 35 (1987), pp. 559-577.

[116] D. W. Turner. "Molecular Photoelectron Spectroscopy". In: Philosophical Transactions of the Royal Society of London. Series A, Mathematical and Physical Sciences 268.1184 (1970), pp. 7-31.

[117] J.L. Olivier, R. Locht, and J. Momigny. "A dissociative electroionization study of nitrous oxide. The $\mathrm{NO}^{+}$and $\mathrm{N}_{2}^{+}$dissociation channels". In: Chemical Physics 68.1-2 (1982), pp. $201-211$.

[118] J.L. Olivier, R. Locht, and J. Momigny. "A dissociative electroionization study of nitrous oxide. The $\mathrm{O}^{+}$and $\mathrm{N}^{+}$dissociation channels". In: Chemical Physics 84.2 (1984), pp. $295-309$.

[119] P. J. Chantry. "Temperature Dependence of Dissociative Attachment in $\mathrm{N}_{2} \mathrm{O}$ ". In: The Journal of Chemical Physics 51.8 (1969), pp. 3369-3379.

[120] M. Aiempanakit et al. "Hysteresis and process stability in reactive high power impulse magnetron sputtering of metal oxides". In: Thin Solid Films 519.22 (2011), pp. 7779-7784.

[121] M. Aiempanakit et al. "Understanding the discharge current behavior in reactive high power impulse magnetron sputtering of oxides". In: Journal of Applied Physics 113.13, 133302 (2013).

[122] M. Audronis, V. Bellido-Gonzalez, and B. Daniel. "Control of reactive high power impulse magnetron sputtering processes". In: Surface and Coatings Technology 204.14 (2010), pp. 2159-2164.

[123] M. Hála et al. "Reactive HiPIMS deposition of $\mathrm{SiO}_{2} / \mathrm{Ta}_{2} \mathrm{O}_{5}$ optical interference filters". In: Journal of Applied Physics 116.21, 213302 (2014). 
[124] N. Martin et al. "Correlation between processing and properties of $\mathrm{TiO}_{x} \mathrm{~N}_{y}$ thin films sputter deposited by the reactive gas pulsing technique". In: Applied Surface Science 185.1-2 (2001), pp. 123-133.

[125] M. Bowes and J.W. Bradley. "The behaviour of negative oxygen ions in the afterglow of a reactive HiPIMS discharge". In: Journal of Physics D: Applied Physics 47.26 (2014), p. 265202.

[126] M. Bowes, P. Poolcharuansin, and J.W. Bradley. "Negative ion energy distributions in reactive HiPIMS". In: Journal of Physics D: Applied Physics 46.4 (2013), p. 045204.

[127] S. Mráz and J.M. Schneider. "Influence of the negative oxygen ions on the structure evolution of transition metal oxide thin films". In: Journal of Applied Physics 100.2, 023503 (2006).

[128] S. Mráz and J.M. Schneider. "Energy distribution of $\mathrm{O}^{-}$ions during reactive magnetron sputtering". In: Applied Physics Letters 89.5, 051502 (2006).

[129] K. Wittmaack. "Ion-induced electron emission as a means of studying energy- and angle-dependent compositional changes of solids bombarded with reactive ions: I. Oxygen bombardment of silicon". In: Surface Science 419.2-3 (1999), pp. 249-264.

[130] M. Hala et al. "Dynamics of reactive high-power impulse magnetron sputtering discharge studied by time- and space-resolved optical emission spectroscopy and fast imaging". In: Journal of Applied Physics 107.4, 043305 (2010).

[131] S. Dupljanin et al. "Transport coefficients and cross sections for electrons in $\mathrm{N}_{2} \mathrm{O}$ and $\mathrm{N}_{2} \mathrm{O} / \mathrm{N}_{2}$ mixtures". In: Plasma Sources Science and Technology 19.2 (2010), p. 025005.

[132] A. Karpinski et al. "Deposition of nickel oxide by direct current reactive sputtering: Effect of oxygen partial pressure". In: Thin Solid Films 520.9 (2012), pp. 3609-3613.

[133] J.C. Sagás, D.A. Duarte, and S.F. Fissmer. "Effect of oxygen concentration and system geometry on the current-voltage relations during reactive sputter deposition of titanium dioxide thin films". In: Vacuum 85.11 (2011), pp. 10421046 .

[134] F. Magnus et al. "Current-voltage-time characteristics of the reactive $\mathrm{Ar} / \mathrm{O}_{2}$ high power impulse magnetron sputtering discharge". In: Journal of Vacuum Science \& Technology A 30.5, 050601 (2012).

[135] M. Samuelsson et al. "Growth of Ti-C nanocomposite films by reactive high power impulse magnetron sputtering under industrial conditions". In: Surface and Coatings Technology 206.8-9 (2012), pp. $2396-2402$.

[136] A. Aijaz et al. "Synthesis of hydrogenated diamondlike carbon thin films using neon-acetylene based high power impulse magnetron sputtering discharges". In: Journal of Vacuum Science \& Technology A: Vacuum, Surfaces, and Films 34.6 (2016), p. 061504. 
[137] P. Souček et al. "Superhard nanocomposite nc-TiC/a-C:H coatings: The effect of HiPIMS on coating microstructure and mechanical properties". In: Surface and Coatings Technology 311.Supplement C (2017), pp. $257-267$.

[138] R. Rejoub, B. G. Lindsay, and R. F. Stebbings. "Determination of the absolute partial and total cross sections for electron-impact ionization of the rare gases". In: Phys. Rev. A 65 (2002), p. 042713.

[139] S.-H. Zheng and S. K. Srivastava. "Electron-impact ionization and dissociative ionization of acetylene". In: Journal of Physics B: Atomic, Molecular and Optical Physics 29.14 (1996), p. 3235.

[140] R. K. Janev and D. Reiter. "Collision processes of $\mathrm{C}_{2,3} \mathrm{H}_{y}$ and $\mathrm{C}_{2,3} \mathrm{H}_{y}^{+}$ hydrocarbons with electrons and protons". In: Physics of Plasmas 11.2 (2004), pp. 780-829.

[141] T. Schmidtová et al. "Study of hybrid PVD-PECVD process of Ti sputtering in argon and acetylene". In: Surface and Coatings Technology 205.Supplement 2 (2011), S299 -S302.

[142] C. Corbella et al. "Structural effects of nanocomposite films of amorphous carbon and metal deposited by pulsed-DC reactive magnetron sputtering". In: Diamond and Related Materials 16.10 (2007), pp. $1828-1834$.

[143] J. Ristein, J. Schäfer, and L. Ley. "Effective correlation energies for defects in a-C:H from a comparison of photelectron yield and electron spin resonance experiments". In: Diamond and Related Materials 4.4 (1995), pp. 508 -516.

[144] H. Saitoh et al. "Work Function of Amorphous Carbon Nitride with Various Functional Groups". In: Japanese Journal of Applied Physics 41.10R (2002), p. 6169.

[145] A. Vetushka and A.P. Ehiasarian. "Plasma dynamic in chromium and titanium HIPIMS discharges". In: Journal of Physics D: Applied Physics 41.1 (2008), p. 015204.

[146] J.T. Gudmundsson et al. "On the electron energy in the high power impulse magnetron sputtering discharge". In: Journal of Applied Physics 105.12, 123302 (2009).

[147] F.F. Chen. "Langmuir probe diagnostics". In: IEEE-ICOPS Meeting, Jeju, Korea. 2003.

[148] F. Brüning et al. "Effects of temperature on the dissociative electron attachment to N2O". In: Chemical Physics Letters 292.1-2 (1998), pp. 177 -182 .

[149] E. de Hoffmann and V. Stroobant. Mass Spectrometry: Principles and Applications. Wiley, 2007.

[150] P. van der Heide. X-Ray Photoelectron Spectroscopy : An Introduction to Principles and Practices. John Wiley \& Sons, 2011.

[151] N. Stojilovic. "Why Can’t We See Hydrogen in X-ray Photoelectron Spectroscopy?" In: Journal of Chemical Education 89.10 (2012), pp. 1331-1332. 
[152] S. Oswald and R. Reiche. "Binding state information from XPS depth profiling: capabilities and limits". In: Applied Surface Science 179.1-4 (2001), pp. 307-315.

[153] P. Cova et al. "A method for the analysis of multiphase bonding structures in amorphous $\mathrm{SiO}_{x} \mathrm{~N}_{y}$ films". In: Journal of Applied Physics 97.7, 073518 (2005).

[154] P. Cova, S. Poulin, and R.A. Masut. "X-ray photoelectron spectroscopy and structural analysis of amorphous $\mathrm{SiO}_{x} \mathrm{~N}_{y}$ films deposited at low temperatures". In: Journal of Applied Physics 98.9, 094903 (2005).

[155] T. Thärigen et al. "Hard amorphous $\mathrm{CSi}_{\mathrm{x}} \mathrm{N}_{y}$ thin films deposited by $\mathrm{RF}$ nitrogen plasma assisted pulsed laser ablation of mixed graphite $/ \mathrm{Si}_{3} \mathrm{~N}_{4}$ targets". In: Thin Solid Films 348.1-2 (1999), pp. 103 -113.

[156] O. Benka. "Elastic Recoil Detection Analysis (ERDA)". In: Surface and Thin Film Analysis. Ed. by G. Friedbacher and H. Bubert. Wiley-VCH Verlag GmbH \& Co. KGaA, 2011, pp. 217-227.

[157] G. Dollinger et al. "High resolution depth profile analysis by elastic recoil detection with heavy ions". In: Fresenius' Journal of Analytical Chemistry 353.3-4 (1995), pp. 311-315.

[158] S.R. Walker et al. "Radiation damage during heavy ion elastic recoil detection analysis of insulating materials". In: Nuclear Instruments and Methods in Physics Research Section B: Beam Interactions with Materials and Atoms 136.Supplement C (1998), pp. $707-712$.

[159] K. Bewilogua and H. Dimigen. "Preparation of W-C:H coatings by reactive magnetron sputtering". In: Surface and Coatings Technology 61.1 (1993), pp. $144-150$.

[160] J. W. Zou et al. "The deposition and study of hard carbon films". In: Journal of Applied Physics 65.10 (1989), pp. 3914-3918.

[161] J. W. Zou et al. "The properties of a-C:H films deposited by plasma decomposition of $\mathrm{C}_{2} \mathrm{H}_{2}$ ". In: Journal of Applied Physics 67.1 (1990), pp. $487-$ 494.

[162] A. C. Ferrari et al. "Density, $\mathrm{sp}^{3}$ fraction, and cross-sectional structure of amorphous carbon films determined by x-ray reflectivity and electron energy-loss spectroscopy". In: Phys. Rev. B 62 (2000), pp. 11089-11103.

[163] P.N. Gibson. "Grazing Incidence X-Ray Methods for Near-Surface Structural Studies". In: Surface and Thin Film Analysis. Ed. by G. Friedbacher and H. Bubert. Wiley-VCH Verlag GmbH \& Co. KGaA, 2011, pp. 311-327.

[164] G.V. Pavlinsky. Fundamentals of X-Ray Physics. Cambridge International Science Publishing, 2008.

[165] J.R. Ferraro and K. Nakamoto. Introductory Raman Spectroscopy. Elsevier Science, 2012.

[166] P. Larkin. Infrared and Raman Spectroscopy: Principles and Spectral Interpretation. Elsevier Science, 2011. 
[167] A. C. Ferrari and J. Robertson. "Resonant Raman spectroscopy of disordered, amorphous, and diamondlike carbon". In: Phys. Rev. B 64 (2001), p. 075414.

[168] A. C. Ferrari, S. E. Rodil, and J. Robertson. "Interpretation of infrared and Raman spectra of amorphous carbon nitrides". In: Phys. Rev. B 67 (2003), p. 155306.

[169] G. Mera et al. "Polymer-derived SiCN and SiOC ceramics - structure and energetics at the nanoscale". In: J. Mater. Chem. A 1 (2013), pp. 3826-3836.

[170] G. Gregori et al. "Microstructure evolution of precursors-derived SiCN ceramics upon thermal treatment between 1000 and $1400{ }^{\circ} \mathrm{C}$ ". In: Journal of Non-Crystalline Solids 351.16-17 (2005), pp. $1393-1402$.

[171] B. Freund and S. Suresh. Thin Film Materials: Stress, Defect Formation and Surface Evolution. Cambridge University Press, 2004.

[172] A.J. Rosakis et al. "Full field measurements of curvature using coherent gradient sensing: application to thin film characterization". In: Thin Solid Films 325.1-2 (1998), pp. 42-54.

[173] G.C.A.M. Janssen et al. "Celebrating the 100th anniversary of the Stoney equation for film stress: Developments from polycrystalline steel strips to single crystal silicon wafers". In: Thin Solid Films 517.6 (2009), pp. 18581867.

[174] W.C. Oliver and G.M. Pharr. "An improved technique for determining hardness and elastic modulus using load and displacement sensing indentation experiments". In: Journal of Materials Research 7.6 (June 1992), pp. $1564-1583$.

[175] H. Tompkins and E.A. Irene. Handbook of Ellipsometry. Elsevier Science, 2005.

[176] G.E. Jellison and F.A. Modine. "Parameterization of the optical functions of amorphous materials in the interband region". In: Applied Physics Letters 69.3 (1996), pp. 371-373.

[177] G.E. Jellison et al. "Spectroscopic ellipsometry characterization of thin-film silicon nitride". In: Thin Solid Films 313-314.0 (1998), pp. 193-197. 
Included publications and author's contribution

\section{List of publications}

I Silicon oxynitride films deposited by reactive high power impulse magnetron sputtering using nitrous oxide as a single-source precursor

T. Hänninen, S. Schmidt, J. Jensen, L. Hultman, and H. Högberg Journal of Vacuum Science and Technology A 33, 05E121 (2015)

II Stoichiometric silicon oxynitride thin films reactively sputtered in $\mathrm{Ar} / \mathrm{N}_{\mathbf{2}} \mathrm{O}$ plasmas by HiPIMS

T. Hänninen, S. Schmidt, J. Wissting, J. Jensen, L. Hultman, and

H. Högberg

Journal of Physics D: Applied Physics 49, 135309 (2016)

III $\mathrm{SiN}_{\mathrm{x}}$ coatings deposited by reactive high power impulse magnetron sputtering: process parameters influencing the nitrogen content S. Schmidt, T. Hänninen, C. Goyenola, J. Wissting, J. Jensen, L. Hultman, N. Goebbels, M. Tobler, and H. Högberg ACS Applied Materials and Interfaces, 8, 20385 (2016)

IV $\operatorname{SiN}_{\mathrm{x}}$ coatings deposited by reactive high power impulse magnetron sputtering: Process parameters influencing the residual coating stress

S. Schmidt, T. Hänninen, J. Wissting, L. Hultman, N. Goebbels,

A. Santana, M. Tobler, and H. Högberg

Journal of Applied Physics, 121, 171904 (2017) 
V Silicon carbonitride thin films deposited by reactive high power impulse magnetron sputtering

T. Hänninen, S. Schmidt, I.G. Ivanov, J. Jensen, L. Hultman, and H. Högberg

Surface and Coatings Technology, 335, 248 (2018)

VI Mechanical properties of SiCN thin films deposited by HiPIMS/DCMS co-sputtering

T. Hänninen, S. Schmidt, J.Lu, L. Hultman, and H. Högberg

Submitted for publication

\section{Author's contribution}

\section{Paper I}

The author designed the study and performed thin film synthesis. The author did the thin film characterization and data analysis, except XPS measurements and ERD analysis. The author wrote the manuscript.

\section{Paper II}

The author designed the study and performed thin film deposition. The author did the thin film characterization and data analysis, except XPS measurements. The author performed the Langmuir probe measurements and data analysis in cooperation with co-authors. The author wrote the manuscript.

\section{Papers III-IV}

The author took part in thin film deposition and residual stress measurements. The author participated in discussing the results and provided comments for the manuscripts.

\section{Paper V}

The author designed the study and performed thin film synthesis. The author did the thin film characterization and data analysis, except XPS, Raman, and ERDA measurements. The author wrote the manuscript.

\section{Paper VI}

The author designed the study and performed thin film deposition. The author did the thin film characterization and data analysis, except XPS measurements, TEM, and surface roughness measurements. The author wrote the manuscript. 


\section{Papers}

The papers associated with this thesis have been removed for copyright reasons. For more details about these see:

http://urn.kb.se/resolve?urn=urn:nbn:se:liu:diva-145177 